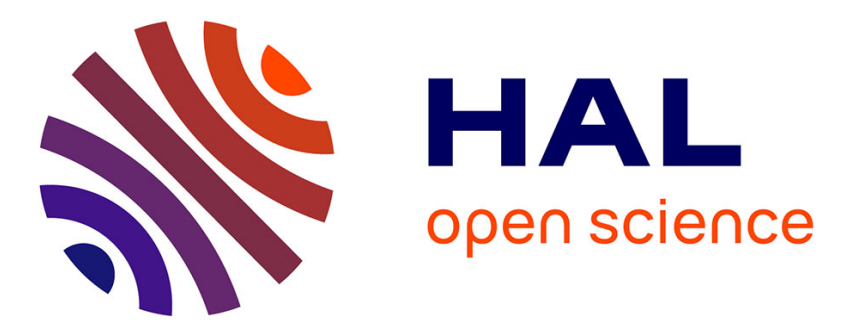

\title{
A new petrological and geophysical investigation of the present-day plumbing system of Mount Vesuvius
}

\author{
Anne Pommier, Pascal Tarits, Sophie Hautot, Michel Pichavant, Bruno \\ Scaillet, Fabrice Gaillard
}

\section{- To cite this version:}

Anne Pommier, Pascal Tarits, Sophie Hautot, Michel Pichavant, Bruno Scaillet, et al.. A new petrological and geophysical investigation of the present-day plumbing system of Mount Vesuvius. Geochemistry, Geophysics, Geosystems, 2010, 11 (7), 23 p. 10.1029/2010GC003059 insu-00492269

\section{HAL Id: insu-00492269 \\ https://hal-insu.archives-ouvertes.fr/insu-00492269}

Submitted on 16 Sep 2010

HAL is a multi-disciplinary open access archive for the deposit and dissemination of scientific research documents, whether they are published or not. The documents may come from teaching and research institutions in France or abroad, or from public or private research centers.
L'archive ouverte pluridisciplinaire HAL, est destinée au dépôt et à la diffusion de documents scientifiques de niveau recherche, publiés ou non, émanant des établissements d'enseignement et de recherche français ou étrangers, des laboratoires publics ou privés. 


\section{A NEW PETROLOGICAL AND GEOPHYSICAL INVESTIGATION OF THE PRESENT-DAY PLUMBING SYSTEM OF MT. VESUVIUS}

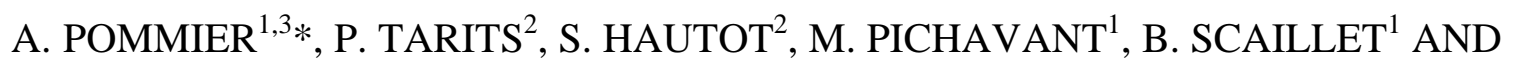
F. GAILLARD ${ }^{1}$

${ }^{1}$ Université d'Orléans, Institut des Sciences de la Terre d'Orléans, UMR 6113, 45067, Orléans, France

CNRS/INSU, Institut des Sciences de la Terre d'Orléans, UMR 6113, 45071 Orléans, France

${ }^{2}$ CNRS/UBO, Institut Universitaire Européen de la Mer, Domaines Océaniques, UMR 6538, Brest, France

${ }^{3}$ Department of Earth, Atmospheric and Planetary Sciences, Massachusetts Institute of Technology, Cambridge, MA 02139, USA.

*Corresponding author. apommier@mit.edu 


\begin{abstract}
A model of the electrical resistivity of Mt. Vesuvius has been elaborated to investigate the present structure of the volcanic edifice. The model is based on electrical conductivity measurements in the laboratory, on geophysical information, in particular, magnetotelluric (MT) data, and on petrological and geochemical constraints. Both 1-D and 3-D simulations explored the effect of depth, volume and resistivity of either one or two reservoirs in the structure. For each configuration tested, modeled MT transfer functions were compared to field transfer functions from field magnetotelluric studies. The field electrical data are reproduced with a shallow and very conductive layer ( $\sim 0.5 \mathrm{~km}$ depth, $1.2 \mathrm{~km}$ thick, 5ohm.m resistive) that most likely corresponds to a saline brine present beneath the volcano. Our results are also compatible with the presence of cooling magma batches at shallow depths $(<3-4 \mathrm{~km}$ depth). The presence of a deeper body at $\sim 8 \mathrm{~km}$ depth, as suggested by seismic studies, is consistent with the observed field transfer functions if such a body has an electrical resistivity $>\sim 100 \mathrm{ohm}$.m. According to a petro-physical conductivity model, such a resistivity value is in agreement either with a low-temperature, crystal-rich magma chamber or with a small quantity of hotter magma interconnected in the resistive surrounding carbonates. However, the low quality of MT field data at long periods prevent from placing strong constraints on a potential deep magma reservoir. A comparison with seismic velocity values tends to support the second hypothesis. Our findings would be consistent with a deep structure $(8-10 \mathrm{~km}$ depth) made of a tephriphonolitic magma at $1000^{\circ} \mathrm{C}$, containing $3.5 \mathrm{wt} \% \mathrm{H} 2 \mathrm{O}, 30 \mathrm{vol} \%$ crystals, and interconnected in carbonates in proportions $\sim 45 \%$ melt - 55\% carbonates.
\end{abstract}

\title{
1. Introduction
}

Mt. Somma-Vesuvius is characterized by a high volcanic risk because of its dangerous past activity in a densely populated area. Its eruptive history has been marked by an alternation of effusive and explosive activity over the last 20kyrs. Since 1944, 
however, Mt. Vesuvius volcano has entered a dormant period, being nowadays characterized only by a widespread but cold fumarolic activity in the inner slopes and bottom of the crater [Chiodini et al., 2001] and a moderate micro-earthquake activity [DeNatale et al., 2006]. Yet, Mt. Vesuvius is still considered as a very dangerous volcano, its volcanic history suggesting that the longer the quiescent period, the more violent the renewal of activity [Santacroce et al., 1994].

The determination of plausible eruptive scenarios in case of volcanic re-awakening has an obvious direct impact on hazard assessment plans in the Neapolitan area. However, large uncertainties remain with respect to the existence of a present magma reservoir and its storage conditions, in particular size and depth. Past eruptions have been widely investigated and their pre-eruptive conditions are well constrained [e.g. Santacroce, 1983; Rosi and Santacroce, 1983; Rolandi et al., 1993; Cioni et al., 1995; Scaillet et al., 2008]. Proposed future scenarios range from a sub-plinian eruption, similar to 472 or 1631 AD eruptions [Scandone et al., 1993; Santacroce et al., 2005] up to devastating AD79 Pompeitype events associated to a larger magma storage zone that would extend well beyond the size of Mt Vesuvius cone [e.g. Auger et al., 2001; Nunziata et al., 2006].

Numerous geophysical studies aimed at investigating the present inner structure beneath Mt. Vesuvius, which is characterized by various seismic, magnetotelluric (MT) and gravimetric anomalies. In particular, a conversion of $\mathrm{P}$ to $\mathrm{S}$ seismic waves has been evidenced at $\sim 8-10 \mathrm{~km}$ depth and interpreted as the top of a large magma sill [Zollo et al., 1996, 1998; Auger et al., 2001; Nunziata et al., 2006]. Such an anomaly has also been detected by the MT study of Di Maio et al. [1998]. However, based on combined timedomain electromagnetic and magnetotelluric soundings (TDEM-MT investigation), Manzella et al. [2004] argue that the conductive anomaly detected below Mt. Vesuvius corresponds to a superficial brine layer rather than to the presence of a deep conductive magma body. This is consistent with the gravimetric observations from Berrino and Camacho [2008] that could not detect the deep anomalous layer interpreted by seismic tomography as an extended sill but attributed the different deep anomalies to solidified magma bodies.

In the present paper, we propose a new approach for an improved characterization of the present day plumbing system of Mt. Vesuvius. We elaborated a model (both 1-D and 3-D) of the electrical resistivity of the upper crust underneath Mt. Vesuvius. This 
model is based on laboratory measurements of electrical resistivity performed on natural Vesuvius samples [Pommier et al., 2008], on petrological information, in particular, the phase equilibrium relationships of Mt. Vesuvius magmas, and on previous geophysical and geochemical studies. The aim of this paper is three-fold: 1) to define the structure of the volcanic complex that best reproduce the field MT data and that matches petrological constraints, 2) to establish the most reliable hypotheses regarding the storage conditions of a potential magma reservoir, and 3) to underline the need for the acquisition of new MT measurements across Mt Vesuvius cone, particularly for deeper investigations with long period data (>100s).

\section{Volcanological background and petrological constraints}

Mt. Somma-Vesuvius volcanic complex probably originated from the regional tensile Quaternary tectonics that dissected the Apennine units and deepened the carbonate basement in the Campanian Plain [Bruno et al., 1998; Bianco et al., 1998]. Mt. Vesuvius area is intersected by two regional sets of faults trending NW-SE and NE-SW [Santacroce, 1987] and its present seismic activity has been attributed to both regional and local stress fields [Marzocchi et al., 1993; Bianco et al., 1998 and references therein; DeNatale et al., 2000].

The volcanic activity of Mt. Somma-Vesuvius started between 18 and 37 ka B.P. [Principe et al., 1999], although the earliest magmatic events in the Vesuvian area go back to ca 400 ka [Brocchini et al., 2001; Di Renzo et al., 2007]. It alternated frequent openconduit activity (effusive eruptions and Strombolian events) with closed conduit conditions, the latter giving rise to Plinian or sub-Plinian eruptions following periods of dormancy lasting several centuries or millennia [Arnò et al., 1987; Santacroce et al., 2008]. The volcano underwent several caldera collapses, produced by at least four Plinian eruptions [Cioni et al., 1999], and the present cone (Mt. Vesuvius) was formed since the famous Pompei eruption in $79 \mathrm{AD}$. Small batches of primitive magmas were discharged during Strombolian events $(<0.001 \mathrm{~km} 3)$ while larger reservoirs of more evolved magmas were involved in Plinian eruptions (from 0.1 to a few km3) [Rosi et al., 1987]. 
The variety of rocks forming the volcanic complex is presented in Table 1 . Geophysical investigations, constrained by one deep drilling (Trecase well), allowed to define the shallow structure of the volcanic edifice. The subsurface of the volcano is made of volcanic deposits (thickness $<3 \mathrm{~km}$ ), consisting of highly fracturated interbedded lava, pyroclastic materials and volcanoclastic, marine and fluvial sedimentary rocks of Pleistocene ages [Santacroce et al., 1983; Zollo et al., 1998, 2002; De Matteis et al., 2000]. The presence of a shallow brine, included within the volcanic-sedimentary deposits and extending vertically down to the top of the underlying carbonates, has been inferred from various geochemical and geophysical lines of evidence [Chiodini et al., 2001; Caliro et al., 2005; Manzella et al., 2004]. The nature of the present-day fluids circulating in this hydrothermal system is a saline liquid phase coexisting with a $\mathrm{CO}_{2}$-rich vapor phase [Chiodini et al., 2001; Caliro et al., 2005], Vesuvian magmas being characterized by both high chlorine and CO2 contents [Cioni et al., 1998; Marianelli et al., 2005; BalconeBoissard et al., 2008], associated to elevated CO2 diffuse emissions [Chiodini et al., 2001; Iacono-Marziano et al., 2009 and references therein]. Seismic and gravimetric surveys indicate that the underlying Mesozoic carbonates have a thickness of $\sim 8 \mathrm{~km}$, the top being at 2-3km depth in Mt. Vesuvius area, deepening westward from the adjacent Apenninic belt [Bruno et al. 1998; De Natale et al., 2004; Cella et al., 2007]. This carbonate thick layer is dissected by normal faults at a regional scale, causing a horst and graben-like structure. The metamorphic Campanian basement is encountered at a depth greater than $11 \mathrm{~km}$, being characterized by a high density $(2,800 \mathrm{~kg} / \mathrm{m} 3)$ [Berrino et al., 1998]. The presence of a deep (mantellic) magma source is poorly constrained but is inferred to lie at $60 \mathrm{~km}$ depth below Mt. Vesuvius [Joron et al., 1987]. It would be located in the mantle wedge consistent with the presence of a subducted lithospheric slab [Panza et al., 2007]. The Moho discontinuity beneath Mt. Vesuvius is located at $\sim 30 \mathrm{~km}$ depth [e.g. Ferrucci et al., 1989].

Mt. Vesuvius magmas are generally highly potassic, ranging from slightly silica undersaturated (K-basalt to trachyte) to highly silica undersaturated (K-tephrite to Kphonolite) [Joron et al., 1987; Ayuso et al., 1998; Iacono-Marziano et al., 2009]. Several petrological and geochemical studies contributed to define the pre-eruptive conditions for the past eruptions [e.g. Rosi and Santacroce, 1983; Civetta and Santacroce, 1992; Villemant et al., 1993; Cioni et al., 1995; Marianelli et al., 1995; Fulignati et al., 2004a; Scaillet et al., 2008]. Pressure, temperature and crystal content of the magmas that were 
involved in the main volcanic events of Mt. Vesuvius, like the Pompei Plinian eruption (79AD), the Pollena subplinian eruption (472 AD) and the last eruptive event from 1944, are presented in Table 1. Petrological and geochemical (isotopic) studies suggest the presence of a "shallow" magmatic system $(<\sim 4 \mathrm{~km})$ periodically recharged with the arrival of K-rich magma batches from a “deep” reservoir (>10km depth) [Marianelli et al., 1995; Cioni et al., 1999; Civetta et al., 2004]. Major differences regard both the depth and the size of the magma chamber [e.g. Santacroce, 1983; Marianelli et al., 1999]. The phase equilibria obtained on various Mt Vesuvius magmas led Scaillet et al. [2008] to conclude that the reservoirs that fed the past eruptions migrated from $7-8 \mathrm{~km}$ to $2-3 \mathrm{~km}$ depth between AD79 and 1944 events [Cioni et al., 1995; Marianelli et al., 1999; Scandone et

al., 2008]. Given that such a shift goes along with an eruptive style, from Plinian to Strombolian [Scaillet et al., 2008], a correct location of the current reservoir depth is central for a proper definition of future eruptive scenarios. The reservoir depth is an important parameter in the forward modeling. The occurrence of high $\mathrm{P}$ wave velocities above $3 \mathrm{~km}$ depth and of local volcano-tectonic earthquakes shallower than $6 \mathrm{~km}$ depth [Bianco et al., 1998; Lomax et al., 2001] suggest that superficial magma reservoirs of significant size are unlikely.

\section{Laboratory and field electrical studies applied to Mt. Vesuvius}

The electrical properties of rocks and melts can be investigated both in laboratory, using impedance measurements obtained during experiments under pressure and temperature [Pommier et al., 2008 and references therein], and in the field from magnetotelluric (MT) investigation. Several studies [e.g. Wannamaker et al., 2008] have shown that laboratory measurements allow to interpret the MT responses, particularly in terms of storage conditions of a partially molten material.

The electrical resistivity of the main parts of the volcanic edifice used in our model is shown in Table 2. The electrical response of various representative Mt. Vesuvius melts (from tephritic to phonolitic compositions) has been studied at high pressure and temperature by Pommier et al. [2008], from which a model to calculate the electrical 
conductivity of Mt Vesuvius magmas as a function of temperature, pressure, chemical composition, including water content and crystal load has been established (Figure 1). This model allows us to estimate the resistivity of the magma stored in the volcanic complex under the different configurations considered in the forward modeling. The aim of the forward modeling is to define the possible range of the different parameters (resistivity, volume, and depth of the reservoir).

A few magnetotelluric studies have been conducted on Mt. Vesuvius [Di Maio et al., 1998; Müller et al., 1999; Manzella et al., 2004; Troiano et al., 2008]. These investigations have provided MT transfer functions at a series of sites on the volcano (Figure 2) presented in form of apparent resistivity and MT impedance phase as a function of the frequency, or the period. These data express the complex electromagnetic induced response of the Earth to the fluctuations of the natural electromagnetic field, which is a function of the distribution of electrical resistivity in the substratum [e.g. Simpson and Bahr, 2005]. Apparent resistivities are shown in the studies from Di Maio et al. [1998] and Manzella et al. [2004]. Only Manzella et al. [2004] show phase data. The position of the stations is presented Figure 2. The apparent resistivities from Manzella et al. and Di Maio et al. show comparable patterns as a function of frequency at all sites on the volcano (see Figure 8 in Di Maio et al. [1998] and Figure 2 in Manzella et al. [2004]).

Manzella et al. [2004] discussed in detail the quality of the MT data acquired in this region affected by local and regional noise. This region seems perturbed by railways DC noise, which is known to produce biased signal on long period MT ( $>1 \mathrm{~s})$. With their limited number of sites and no remote reference, Manzella et al. could not characterize quantitatively the long period noise which was suspected in the observations by a rapid increase in apparent resistivity and a phase close to zero at periods more than 1-10 s. However while Manzella et al. modeled their data set with emphasis on periods less or equal to $1 \mathrm{~s}$, the resulting models could fit reasonably well the apparent resistivity and to some extent the phase at some sites (Fig 4. in Manzella et al. [2004]). This observation suggests that although the long period noise is present and clearly seen in the phases going to zero, the structure of the data is in first approximation coherent with earth models. As a result in this study, we considered the data by Manzella et al. 2004 suitable to investigate further the structure of the volcano. 
This observation suggests that 1) the horizontal structure at the scale of the volcanic edifice may be considered homogeneous to a first approximation, and 2) smallscale heterogeneities at depth affect only mildly the MT transfer functions. The values of the apparent resistivity between the two MT studies are however shifted one with respect to the other (Figure 3). Apparent resistivity values from Di Maio et al. [1998] are 2 log unit higher than the values from Manzella et al. [2004]. As stressed out by Manzella et al. [2004], the data from Di Maio et al. [1998] are probably distorted by static shift effects, which, in contrast, have been taken into account by Manzella et al. [2004]. According to Troiano et al. [2008], the phases obtained by Di Maio et al. (unfortunately not published) show no significant differences with the phases of Manzella et al. [2004]. This observation is in agreement with a static shift in the data from Di Maio et al., since static shift corresponds by definition to a frequency-independent offset of the magnitudes of MT transfer functions that leaves impedance phases unchanged [e.g. Simpson and Bahr, 2005]. The interpretation of the transfer functions by Di Maio et al. [1998] and Manzella et al. [2004] are also very different. Di Maio et al. interpret the change in apparent resistivity by the presence of a magma reservoir located at $\sim 8 \mathrm{~km}$ depth, in agreement with some seismic studies (Zollo et al., 1998; Auger et al., 2001), while Manzella et al. attribute the observed apparent resistivity changes to a shallow conductive brine layer and no deep reservoir is defined.

\section{Petro-physical resistivity model}

\subsection{Field and laboratory resistivities used in the forward modeling}

In this study, we consider that the data set by Manzella et al. 2004 is suitable to investigate whether a possible deep reservoir suggested by several authors is resolved by MT. Both apparent resistivity and phase are available. They are corrected for static shift and the MT penetration depth (e.g. Simpson and Bahr, 2005) is probably large enough to allow us to infer possible structures at depths greater than $4 \mathrm{~km}$. However, as underlined by Manzella et al., the low frequency MT data $(<1 \mathrm{~Hz})$ are probably strongly affected by coherent electromagnetic noise. Clearly, this problem of the quality of the data prevents from making strong conclusions as regards the deep structure of Mt. Vesuvius. But if they are used together with petrological constraints and other geophysical (seismic) data, these MT data can allow the formulation of likely hypotheses regarding the present state 
of the deep structure of the volcano. On the other hand, the number of sites is too small for a thorough 3-D inversion. A different approach is used here. We defined a resistivity model of the volcano edifice based on our knowledge of the lithology, of the resistivity of the main parts of the volcano, and of a petro-physical model of the electrical resistivity of Vesuvius magmas. With this model, we simulated the MT response functions and compared them to the data from Manzella et al. (2004). The aim of these simulations was to define the possible range of the different parameters of shallow and deep reservoirs (resistivity, volume, and depth).

The electrical resistivity of the main parts of the volcanic edifice is shown in Table 2. The characteristics (depth, thickness and volume) of the volcanic deposits, the brine layer, the underlying carbonates and basement as well as the magma reservoir came from geophysical and petrological previous studies (see references in Table 1). The resistivity values of the volcanic deposits, the carbonates and the basement were obtained after the studies of Di Maio et al. [1998] and Manzella et al. [2004], while the resistivity values of the brine and the magma were determined using electrical measurements in laboratory (respectively Quist and Marshall [1968] and Pommier et al. [2008]). The resistivity of the magma stored in the volcanic complex under the different configurations considered in our MT simulations was estimated using the petro-physical model of Pommier et al. [2008].

In order to obtain a resistivity value for the brine, we considered a two-phase material, composed by volcanic deposits and a $\mathrm{NaCl}$ aqueous solution under the conditions of Chiodini et al., [2001] (Table 1). We assumed that the effect of the CO2 vapor phase on brine resistivity is negligible compared to the effect of the dissolved $\mathrm{NaCl}$. The resistivity of the $\mathrm{NaCl}$ solution was determined using data from the literature [Quist and Marshall, 1968]. The resistivity of magmatic liquids was determined using the model of Pommier et al. [2008], as explained above. Two hypotheses were considered for the calculation of the bulk resistivity of the corresponding magma reservoir, either the reservoir was a mixture of magma and a solid matrix (carbonates or volcanic deposits) or it was a homogeneous “chamber” filled with partially crystallized magma.

The Hashin-Shtrikman upper bound, denoted HS+, was used to calculate the bulk resistivity of the two-phase mixture (either brine or magma reservoir) [Hashin and Shtrikman, 1962]. This model considers a high-conductivity liquid phase (in our case, 
$\mathrm{NaCl}$ solution or magma) surrounding a less conductive material (carbonates or volcanic deposits) [Ten Grotenhuis et al., 2005]. The effective conductivity (or resistivity) is given by:

$$
\sigma_{\text {eff }}=\frac{1}{\rho_{\text {eff }}}=\sigma_{1}+\frac{1-X_{1}}{1 /\left(\sigma_{2}-\sigma_{1}\right)+X_{1} / 3 \sigma_{1}}
$$

where $\int_{\text {eff }}$ and $\rangle_{\text {eff }}$ are respectively the effective conductivity and resistivity of the twophase material, $\int_{1}$ is the conductivity of phase $1, \int_{2}$ is the conductivity of phase $2, \mathrm{X}_{1}$ and $\mathrm{X}_{2}$ are the proportions (volume fraction) of the two phases $\left(\mathrm{X}_{1}=1-\mathrm{X}_{2}\right)$. Resistivity values calculated using the Hashin-Shtrikman formalism were found to match the resistivity range provided by the modified Archie's law [Glover et al. 2000; Pommier et al., 2008], suggesting that both models can be used to estimate the resistivity of the two-phase mixtures considered in this study.

\subsection{Strategy}

Our preliminary modeling strategy consisted in calculating 1-D resistivity models at each station of Manzella et al. [2004], using the MTInv program of the University of Oulu [Pirttijärvi, 2004]. The initial three-layer model represented the volcanic deposits, the carbonates-basement and the deep magma source (the half-space). Thicknesses and resistivity values come from the literature (see references in Table 1) and the characteristics of these layers are presented in Table 2. We merged the carbonates and the basement into one single layer, because of their similar resistivity values (Table 1). We added a conductive layer, figuring either the brine layer suggested by Manzella et al. 2004 or a large magma reservoir (Di Maio et al. 1998, Zollo et al. 1998). We also considered cases with the two conductive bodies.

The 1-D simulations were extended to 3-D in order to account for the finite size of the magma chamber and to test the impact of major features on the data, such as the coast effect, the topography, the graben-like structure and the carbonates deepening (see section 2). The 3-D forward problem is solved with the finite difference algorithm proposed by Mackie et al. [1993]. An example of 3-D model is presented in Figure 4. The grid used for 3-D modeling covers the entire Vesuvius area and is centered on the volcano. A higher 
resolution was adopted in the central area. The model is parameterized by 50 blocks in the $\mathrm{x}$ direction, 50 blocks in the y direction (see spatial orientation in Figure 2) and 37 layers in the vertical, $\mathrm{z}$ direction. We used a set of 17 periods from $0.1-1000$ s for the modeling. This period range matches those from Di Maio et al.[1998] and Manzella et al.[2004].

\subsection{Negligible structures and topography effect}

Before using the 3-D model to investigate the effect of a magma chamber, notably its volume, we tested the influence of the main known resistivity contrasts. The 3-D structures were embedded into a mean 1-D model derived from the values in Tables 1 and 2 (Figure 4). At first, we included in the model the limits of the shoreline. The value of the electrical resistivity of the sea water was taken to $0.3 \mathrm{ohm} . \mathrm{m}$. We found this effect negligible at the sites on the volcano in the period range of interest (less than 200 s). Some structural characteristics like the graben-like structure and the carbonates deepening were also included in the first 3-D simulations. Their influence on the MT transfer functions was also found negligible, owing to 1) a too low contrast in resistivity between the volcanic deposits and the carbonates and 2) the small dimensions of both the graben and the westward deepening. The inclusion of topography turned out to be numerically challenging. Edge points represented the main problem for modeling the topography when topographic steps were beside a site. We observed that the topography effect calculated numerically was essentially responsible for static shifts at the observation sites. We concluded that the corrections carried out by Manzella et al. (2004) were taking care of this problem. While this is probably a severe approximation, we did not find in the modeling any self-induction of the static shift that could have biased the corrected response function of Manzella et al. (2004). These corrections have probably taken care of other superficial local static shift effects as well. We trust that the resulting corrected data are representative of the main induction processes in the volcano that may be modeled with a flat model. This hypothesis has to be tested further with a more complete set of data.

\section{Results}


The petro-physical 1-D model described in the previous section comprised volcanic deposits, the association carbonate-basement and the deep magma source (as half-space), their thickness and resistivity being listed in Tables 1 and 2. The electrical response of this initial model is presented in Figures 5a and 5b. This model clearly did not reproduce the observation. The data require a conductive layer, as suggested by Manzella et al. [2004]. With the addition of such a layer, the parameters (depth, thickness and resistivity) of the model were varied in order to fit the observed MT transfer functions. We introduced a shallow conductive layer and subsequently a 1-D and a 3-D conductive structure at a greater depth. The main parameters considered in the 3-D modeling were the depth, the volume and the resistivity value (i.e. the composition) of the deep conductive 3$\mathrm{D}$ body. Because of the low quality of field data at high periods, we essentially compare modeled MT transfer functions for different configurations of the deep volcanic structure.

\subsection{Effect of a superficial conductor}

The shallow conductive layer introduced in the 1-D model was set at depths ranging from a few hundreds $\mathrm{m}$ to a few $\mathrm{km}$. The presence of a conductive layer resulted in a minimum in the apparent resistivity curve as well as a decrease in the impedance phase. The effect of the resistivity of this layer is presented in Figure 5a. This trend is observed in the data of both Di Maio [1998] et al and Manzella et al. [2004] at periods 15s. For each site, the field data from Manzella et al. [2004] were successfully fitted when the top of the conductive layer is at 0.2 to $0.6 \mathrm{~km}$ depth, with a resistivity of $\sim 4-5 \mathrm{ohm}$.m and a thickness ranging between 1 and $1.7 \mathrm{~km}$, depending on the site position (Figure $5 \mathrm{~b}$ ). These parameters did not change much from one site to the other. Hence, based on the layer models obtained for each site, a general 1-D model of the electrical resistivity below Mt. Vesuvius was defined and is shown on Figure 5c. The superficial conductive layer represents the main conductive body below the volcano, since the field data are

reproduced by its only presence. Note that the resistivity here is the effective resistivity described in the previous section.

\subsection{Effect of a deep conductive body}


Several 1-D simulations were performed to investigate the effect of a deep additional layer on the MT transfer functions. The shallow conductive layer was not included. The parameters were varied as follow: depth from 3 to $15 \mathrm{~km}$, thickness from 0.1 to $2 \mathrm{~km}$, resistivity from 0.3 to $2000 \mathrm{ohm}$.m. These wide ranges of values allow numerous configurations of the deep structure below the volcano to be tested. The main results of these simulations are presented in Figure 6. In particular, several simulations were performed with a $20 \mathrm{ohm} . \mathrm{m}$-resistive layer placed at $8 \mathrm{~km}$ depth, since these values are in agreement with the anomaly detected by Di Maio et al. [1998] as well with the value proposed for magma storage by seismic studies [Zollo et al., 1996; Auger et al., 2001].

As shown in Figure 6, the effect of the resistivity value of the layer is visible at periods $>0.1 \mathrm{~s}$. The shape of the transfer functions is affected if the resistivity of the conductive layer is $<\sim 100 \mathrm{ohm} . \mathrm{m}$. For high resistivity values, the curves are similar to the one obtained with the initial model (i.e. with no additional layer, Figure 6a). Increasing the depth of the conductive layer (20ohm.m) increases the apparent resistivity and the phase (Figure 6b). The curves obtained when placing a conductive body at great depths do not fit well the data, whatever the resistivity and thickness. Increasing the thickness of the layer jointly decreases the apparent resistivity and increases the phase (Figure 6c). Increasing the thickness from 1 to $2 \mathrm{~km}$ decreases the apparent resistivity from around 200ohm.m at $\mathrm{T}>2 \mathrm{~s}$ and increases the phase of $\sim 10^{\circ}$ until 20s. Figure 6 underlines that a good fit to the field data is not achieved when a deep conductive layer alone is imposed in the initial model. This is probably partly due to a problem of the quality of the field data at these high periods but it may also provide pieces of information as regard the presence of one or more conductive bodies below Mt. Vesuvius. Whatever the values of the parameters of the conductive layer, the MT data are not reproduced by the presence of this single deep conductor.

\subsection{Joint effect of shallow and deep conductive bodies}

Calculations with two conductive bodies placed respectively at shallow and large depths were performed using 1-D and 3-D simulations. The conditions on the shallow layer were fixed according to the 1-D model presented in Figure 5c. The 3-D simulations serve principally to investigate the effect of the volume of the conductive deep reservoir on the transfer functions. 
As shown on Figure 7, the effect of a deep conductive layer on the transfer functions, when a shallow conductive body is present in the model, is visible for periods > 1s. For example, a $1 \mathrm{~km}$-thick conductive layer placed at $5 \mathrm{~km}$ depth with a very low resistivity (4ohm.m) has an effect at long periods on the apparent resistivity values < 60ohm.m and on the phase values $<30^{\circ}$. A highly conductive deep body is therefore detectable in this period range on both the apparent resistivity and phase values. The effect of the depth of this deep conductor (here 5ohm.m) is presented in Figure 8 for periods larger than 1s. A significant effect on the MT transfer functions is observed when changing the depth from 4 to $15 \mathrm{~km}$. In summary, the presence of an extended thin conductive layer simulating an infinite magma chamber impacts the MT transfer functions significantly at the longest periods available and increases the misfit between the model response and the data in this period range.

Using the 3-D simulation, we tested on the MT transfer functions the effect of the volume of a 20ohm.m conductor -in agreement with the resistivity value proposed by $\mathrm{Di}$ Maio et al. [1998] -of finite size located at 8km depth as suggested by Auger et al. [2001] (Figure 9a). The largest differences in apparent resistivity and phase between a model with no deep reservoir and a model with a very extended 20ohm.m-resistive body (equivalent to a 1-D layer) reach a few tens of ohm.m and a few degrees, respectively, as noticed in Figure 8. When the body is of smaller size, a clear difference between the two perpendicular response functions ( $\mathrm{xy}$ and $\mathrm{yx}$ ) is observed. We also observed that these relatively small bodies several $\mathrm{km}$ in depth did not produce appreciable diagonal components in the MT transfer function tensor. The overall change in the apparent resistivity and phase is smaller than for the infinite case, nevertheless substantial. Figure 9b proposes another way to visualize and to explore the volume effect on the apparent resistivity. We present the apparent resistivity as a function of the deep reservoir volume for different periods. For all periods, the misfit is the smallest for small volume, excepted at 1 s period at which no effect of the conductive body is visible (Figure 9a). Should the field data at high periods be usable, the trend suggests that a large magma chamber does not reproduce the field data well.

Figure 10 presents the effect on the MT transfer functions of the electrical resistivity of an infinite (1-D) $2 \mathrm{~km}$ thick deep conductor, placed at $8 \mathrm{~km}$ depth (in agreement with Auger et al. [2001]). The misfit between the data and the model response increases significantly at long periods when the deep layer has a bulk resistivity smaller 
than $~ 100 \mathrm{ohm}$.m. In Figure 9a, this was the 1-D infinite magma chamber that maximized the misfit. Here, for this end member case, the misfit is minimized - or equivalently the best fit to the field data is obtained - with a resistive deep reservoir, with a bulk resistivity > 100ohm.m.

\section{Discussion}

MT response functions provided by the 1-D and 3-D simulations reproduced successfully the field data. The presence of a shallow conductive structure at a depth $<\sim 2 \mathrm{~km}$ proposed by Manzella et al. [2004] was confirmed. This conductor was observed beneath all sites and could indicate a highly conductive brine [Manzella et al., 2004]. While such a conductor should filter out appreciably the effect of the deep structures, our modeling based on geological and petro-physical constraints suggested that a large magma chamber at depths proposed by other geophysical investigations [e.g. Nunziata et al., 2006] should have produced a detectable signature at the longest periods available in the data set (1-200s). Even if field data are limited in number and probably affected by coherent electromagnetic noise (MT phases are particularly noisy), the effect of a large magma chamber is likely above the noise level, especially on the apparent resistivity. At the proposed depth of $\sim 8 \mathrm{~km}$ [Zollo et al., 1998; Auger et al., 2001], the modeling provided a lower bound for the bulk (or effective) resistivity value of the magma chamber ( 100ohm.m).

\subsection{Shallow brine}

The presence of gas-steam escaping at the summit of Mt Vesuvius suggests that a large amount of hot saline water is present at depth [Chiodini et al., 2001]. The gas-steam is probably of meteoric origin, as observed on other volcanic systems [e.g. Zimmer and Erzinger, 1998]. As suggested by Manzella et al. [2004], hot saline water would be responsible for the observed low resistivity detected by MT data. Our results are consistent with this result, since the MT field data are reproduced by the only presence of 
a shallow conductor with a resistivity of about $\sim 4-50 h m$.m (Figure 5) located at a depth $<2 \mathrm{~km}$. The conductor depth is in agreement with the observations made by Chiodini et al., [2001] and Manzella et al. [2004]. Using a modified Archie’s law [Glover et al., 2000], $\sim 4-5$ hm.m corresponds to a mixture of $98 \%$ volcanic deposits and $2 \% \mathrm{NaCl}$ solution (2$3 \mathrm{~m}$ in concentration, $450^{\circ} \mathrm{C}$, Tables 1 and 2). The salinity of this hot shallow aquifer provides a sufficient amount of conducting material to explain the modeled bulk conductivity. Hydrothermal brine is likely to cause the high conductivity detected in the transfer functions, thus representing the main present-day conductive body below Mt. Vesuvius.

The large thickness of the brine determined in the forward layer model $(\sim 1.2 \mathrm{~km}$ thick, Figure 5c) is consistent with what has been detected on other volcanic edifices. For instance, $1 \mathrm{~km}$-thick brines with resistivities < $10 \mathrm{ohm}$.m have been also inferred at Mt. Unzen [Kagiyama et al., 1999], Merapi [Müller and Haak, 2004], and Mt. Fuji [Aizawa et al., 2005] volcanoes. The presence of such a thick brine may be explained by the fact that meteoric and hydrothermal fluids probably circulate during several tens of thousand years in the shallow depths of the volcanic structure.

\subsection{A magma chamber at shallow depth $(<3-4 \mathrm{~km})$ ?}

\subsubsection{The case for a shallow magma chamber}

The hypothesis of a shallow magma reservoir originates from the documented decrease of the magma chamber depth with time [Scaillet et al., 2008] and by the fact that small shallow reservoirs located at $\sim 2-4 \mathrm{~km}$ depth were involved in the last eruptive events (1906 and 1944 eruptions), [Santacroce et al., 1993; Marianelli et al., 1999; Scandone et al., 2008]. It has been underlined that the shallower the reservoir, the hotter the erupted magma [Scaillet et al., 2008]: pre-eruptive magma temperature for the eruptions of 1906 and 1944 (reservoir depth at about $2 \mathrm{~km}$ ) is estimated at $1100^{\circ} \mathrm{C}$ [e.g. Fulignati et al., 2004b], while for the Pompei eruption (reservoir depth at about 6-8km), it is at $815^{\circ} \mathrm{C}$ (Cioni et al., 1995; Scaillet et al., 2008]. The resistivity of a shallow magma can be very low and would thus fit well into the $\sim 4-50 h m$.m-resistive structure present at shallow depths (Figure 5c). Pommier et al. [2008] have shown that Mt. Vesuvius magmas can be as conductive as a brine. For example, the resistivity of tephritic to phonolitic magmas 
under specific conditions ranges between $\sim 1$ and 5ohm.m at $1000^{\circ} \mathrm{C}$, for typical magmatic crystal contents at Mt Vesuvius (Figure 1).

The volumes of the shallow magma chambers at Mt. Vesuvius have been estimated to be a few tenths of $\mathrm{km}^{3}$ [e.g. Santacroce, 1987], corresponding to a cube in edge line smaller than $\sim 300 \mathrm{~m}$. Seismic studies also have suggested that potential shallow reservoirs of significant size are unlikely [Bianco et al., 1998; Lomax et al., 2001]. Such a small conductive body could explain the minimum in apparent resistivity and the decrease in phase curves for observation sites close to the center of the volcano. However, it would be unable to reproduce the similar transfer functions obtained at sites far from the crater, like Sites 3 and 4 in Di Maio et al. [1998] (see Figure 2). Therefore, we suggest that a brine of large lateral extension is the main conductive shallow body below Mt. Vesuvius. This does not rule out the possibility that a cold magma body is present at shallow depths below the volcano. However, any such body should be sufficiently resistive so as not to affect significantly the transfer functions obtained at sites close to the crater.

\subsubsection{Unerupted magmas from the 1631-1944 period}

Several studies have suggested that no input of fresh magma at shallow depths occurred after the end of the last eruptive event [Chiodini et al., 2001; De Natale et al., 2004]. The 1631-1944 period probably left unerupted magmas shallow in the volcanic edifice that are probably the thermal source of the hydrothermal brines. As suggested by Chiodini et al. [2001], the observed decrease in the temperature of the crater fumaroles (from $\sim 700$ to $95^{\circ} \mathrm{C}$ between 1944 and the present time) is best explained by the progressive cooling of shallow magma bodies. These residual batches could correspond to the shallow bodies evidenced in the gravity study of Berrino et al. [1998] since they have a lower density than the density of the surrounding volcanic deposits (2100 and $2400 \mathrm{~kg} / \mathrm{m} 3$, respectively). With progressive cooling, the resistivity of the magma increases, as modeled by Pommier et al. [2008] and as observed on other volcanoes [e.g. Matsushima et al., 2001]. The bulk resistivity of cooling magma batches at Mt. Vesuvius would thus be higher than $\sim 4-5 \mathrm{ohm}$.m. For example, a hydrous tephriphonolitic magma (3.5wt\% $\left.\mathrm{H}_{2} \mathrm{O}\right)$ containing $80 \mathrm{vol} \%$ crystals (leucite and clinopyroxene) at $700^{\circ} \mathrm{C}$ has a resistivity of $\sim 200 \mathrm{ohm} . \mathrm{m}$, which is within the range of resistivity of the volcanic deposits 
( 100-300ohm.m). These cooling magma batches would be hardly detectable by the MT soundings (irrespective from their size).

\subsection{Possible deep (>3-4km) magma chamber beneath Mt. Vesuvius}

As underlined in Figure 7, the presence at shallow depths of the high conductive brine is probably responsible for a screen effect that makes detection of deeper conductive bodies difficult. Deep anomalies below a superficial conductive layer are detectable by the MT method in volcanic contexts [e.g. Whaler and Hautot, 2006; Umeda et al., 2006]. However, their detectability requires a large volume (several tens of km3) of very conductive magma $(><10 \mathrm{ohm} . \mathrm{m})$. A crystal-rich magma body would be difficult to detect at Mt. Vesuvius because of a low resistivity contrast with the surrounding carbonates. As suggested by Figure 9a, it would also be difficult to detect a small magma chamber below the conductive superficial brine even if the magma resistivity is low. The volume of the magma chambers located at depths $\varepsilon 3-4 \mathrm{~km}$ that fed the Pollena and Pompei eruptions was estimated to be a few $\mathrm{km}^{3}$ [Rosi et al., 1987]. More generally, the maximum volume of magma chambers for the past eruptions during the last 20kyrs is a few $\mathrm{km}^{3}$ [e.g. Santacroce, 1983]. Considering a mean alimentation rate at Mt Vesuvius of 1.6.10$3 \mathrm{~km}^{3} / \mathrm{yr}$, in agreement with the estimation made by Rosi et al. [1987], a volume of $0.104 \mathrm{~km}^{3}$ of fresh magma could be stored since 1944 eruption. Since a conductive body below the brine is hardly detectable (Figure 7), these small volumes of magma will only slightly affect the transfer functions. Therefore, even considering the hypothesis of an input of fresh magma, the MT response functions would not significantly change because the volume of hot magma would be very small.

From the forward model simulations, we inferred that a very large and hot magma chamber, of an extension much larger than the size of Mt Vesuvius cone, is not likely. As shown in Figure 9b, such a reservoir did not provide the best fit to the data. Should this result be confirmed by less noisy field data, it would contrast with the interpretation of several seismic experiments [Zollo et al., 1996, 1998; Auger et al., 2001; Nunziata et al., 2006] that suggest the presence of an extended $\left(>400 \mathrm{~km}^{2}\right.$ and $1-2 \mathrm{~km}$ thick, according to Auger et al. [2001]) low-velocity layer at 8-10km depth. However, both lateral and vertical extensions of the deep anomaly are difficult to constrain from seismic data, as 
stressed by Zollo et al. [1998]. Our simulation results are consistent with the gravimetric observations from Berrino et al. [1998] and Berrino and Camacho [2008] that did not detect a potentially extended magma reservoir below Mt Vesuvius. It is likely that a large deep anomaly would affect gravimetric profiles, since the density of molten magma $\left(<2,480 \mathrm{~kg} / \mathrm{m}^{3}\right.$, Cassano and La Torre, 1987) is significantly lower than that of the surrounding carbonates $\left(2,600-2,800 \mathrm{~kg} / \mathrm{m}^{3}\right.$, Berrino et al., 1998). The deep anomalies detected by gravimetric studies were interpreted as solidified magma bodies [De Natale et al., 2004; Berrino and Camacho, 2008]. More generally, we note that the unlikely presence of an extended hot magma reservoir also represents a case against a potential interconnection of Mt Vesuvius and Phlegrean Fields feeding systems.

Our forward model showed that the existence of a deep conductor did not significantly improve the fit to the field data and tend to suggest that field data can be reproduced by the sole presence of the superficial brine (Figure 7). However, the model is also compatible with the presence of a deep level of magma storage. The field response is indeed still reproduced when a resistive reservoir is placed at depth, as long as the bulk electrical resistivity of the magma storage zone is $>100 \mathrm{ohm} . \mathrm{m}$ (Figure 10). Using the modified Archie’s law (Eq. 1) and the Hashin-Shtrikman formalism [Glover et al., 2000; Hashin and Shtrikman, 1962], a resistive anomaly $>100 \mathrm{ohm} . \mathrm{m}$ allows two hypotheses to be considered (Figure 11). A first hypothesis (hypothesis \#1) considers the presence of a waning chamber. According to the model of Pommier et al., [2008], a magma resistivity $>100 \mathrm{ohm}$.m would correspond to phonolitic or tephriphonolitic melts at $800^{\circ} \mathrm{C}$, with 6 or $4 \mathrm{wt} \% \mathrm{H}_{2} \mathrm{O}$ respectively, and with a crystal content (clinopyroxene) $>80 \%$ vol. It would thus be consistent with a low-temperature, crystal-rich magma chamber. This deep reservoir could be in the final stage of solidification, i.e. hardly or not eruptable. A second hypothesis (hypothesis \#2) considers the presence of a deep growing magma chamber. In this case, the magmatic system would be composed of a magma with a crystal content that matches pre-eruptive conditions (i.e. 20-30\% crystals, Figure 1), interconnected in the more resistive carbonates. The quantity of magma requested to match a bulk resistivity value of $100 \mathrm{ohm} . \mathrm{m}$ corresponds for example to $\sim 30 \%$ of a tephriphonolitic magma $\left(800^{\circ} \mathrm{C}, 4 \mathrm{wt} \% \mathrm{H}_{2} \mathrm{O}, 25 \mathrm{vol} . \%\right.$ crystals) interconnected in $70 \%$ carbonates or to $\sim 2 \%$ of the same magma at $1000^{\circ} \mathrm{C}$ (fully liquid) interconnected in $98 \%$ carbonates [Glover et al., 2000; Pommier et al., 2008]. 


\subsection{Comparison with seismic studies}

As mentioned above, the results from our simulations are compatible with a lowconductive reservoir whose depth is in agreement with the depth of the anomaly detected by seismic studies (8-10km) [Zollo et al., 1996, 1998; Auger et al., 2001]. However, even if our results at periods $>1$ s would deserve being compared to high-quality field data, our study would tend to suggest that the reservoir size is probably smaller than the size proposed by seismic interpretations. Still, $\mathrm{P}$ and $\mathrm{S}$ waves values depend on the material properties and can thus be compared to the two hypotheses regarding magma storage conditions formulated on the basis of our model (Figure 11). The low-velocity zone, interpreted as a partially molten layer [Zollo et al., 1996, 1998; Auger et al., 2001, Nunziata et al., 2006], is characterized by Vs values of about $0.6-1 \mathrm{~km} / \mathrm{s}$ and Vp values $<3 \mathrm{~km} / \mathrm{s}$. Since the seismic properties depend on the composition and microstructure of melt and crystals, models have been proposed to relate seismic waves to properties of partially molten rocks, principally based on the effective media theory [Mainprice, 1997; Taylor and Singh, 2002]. Partial melt can explain the seismic velocity values recorded below Mt. Vesuvius, but it is important to note that a well-defined melt fraction is difficult to determine due to the wide range of values inferred from different experimental results [Rondenay et al., submitted]. We considered the two hypotheses presented in Figure 11. According to the models from Mainprice [1997] and Taylor and Singh [2002], a reservoir filled with a liquid matrix and solid inclusions (crystals) (hypothesis \#1, Figure 11) would have $\mathrm{Vp}$ values well above $3 \mathrm{~km} / \mathrm{s}$, which is not in agreement with the $\mathrm{Vp}$ values measured in seismic studies.

We considered the model of Mainprice [1997] to test hypothesis \#2. Based on Vs and $\mathrm{Vp}$ values, this model provides an estimation of the fraction of a low-polymerized melt at $1200^{\circ} \mathrm{C}$ connected in a denser rock matrix at 6-8km depth. However, petrological studies have shown that Mt Vesuvius magmas stored at these depths probably have lower temperatures, $\left(800^{\circ} \mathrm{C}-1100^{\circ} \mathrm{C}\right)$ (Table 1$)$. Laboratory seismic studies have underlined that decreasing the melt temperature increases Vs and Vp values [e.g., Caricchi et al., 2008]. Seismic models also suggest that $\mathrm{S}$ and $\mathrm{P}$-waves values will be unchanged if the fraction of a colder melt decreases. According to the study of Caricchi et al. [2008] and the model of Mainprice [1997], the Vs and Vp values recorded below Mt Vesuvius appear to be in 
agreement with $>50 \%$ of melt stored at $1200^{\circ} \mathrm{C}$ interconnected in $<50 \%$ of carbonates (rock matrix). Since such an anomaly has a minimum bulk electrical resistivity of $100 \mathrm{ohm} . \mathrm{m}$, a minimum resistivity of the melt of about $50 \mathrm{ohm} . \mathrm{m}$ is calculated using the modified Archie's law. This resistivity range is in agreement with a primitive K-basaltic magma near liquidus containing $3 \mathrm{wt} \% \mathrm{H}_{2} \mathrm{O}$ [Pommier et al., 2008]. For melt temperatures lower than $\sim 1100^{\circ} \mathrm{C}$, the field value of Vs is in agreement with a greater melt fraction (and, thus, a smaller carbonate proportions), while the field value of $\mathrm{Vp}$ is too low to be reproduced by the seismic model of Mainprice [1997]. For instance, the Vs value (0.6$1 \mathrm{~km} / \mathrm{s}$ ) is in agreement with $>60 \%$ of melt stored $800^{\circ} \mathrm{C}$ and $<40 \%$ carbonates but the $\mathrm{Vp}$ value $(<3 \mathrm{~km} / \mathrm{s})$ corresponding to these conditions is estimated to be $>4 \mathrm{~km} / \mathrm{s}$. Hence, when considered together, the results from both magnetotelluric and seismic studies suggested that the deep geophysical anomaly could be due to a hot magma interconnected in the surrounding carbonates.

\section{Conclusions}

A model of the electrical resistivity of Mt. Vesuvius was elaborated using the available electrical measurements in laboratory, geophysical data and petrological constraints. This model reproduces successfully the field data from magnetotellurics studies. Although the field data are of low quality, particularly at periods $>1$ s, their combination with petrological constraints allowed the formulation of likely hypotheses as regards the present state of Mt. Vesuvius. The shallow brine was identified as the main conductive body beneath the volcano since the field transfer functions are reproduced by its only presence. Regarding the occurrence of a shallow magma reservoir, the presence of cooling magma was found to be possible, whereas the hypothesis of a hot magma appears unlikely, although it could not be totally excluded. Both 1-D and 3-D simulations showed that the resistivity of a conductive reservoir located at $8-10 \mathrm{~km}$ depth should be $>100 \mathrm{ohm} . \mathrm{m}$. The model would also tend to suggest that the volume of the reservoir was unlikely to extend spatially well beyond the cone dimensions. Our findings suggested that the deep anomaly detected by geophysical studies could correspond to either a lowtemperature and crystal-rich magma or a hotter magma interconnected within the 
surrounding carbonates. A comparison with seismic wave velocity values, using seismic models to interpret wave velocities in terms of magma structure, favored the second hypothesis. The quantity and the quality of MT data at Mt Vesuvius are nevertheless the main limit to the forward modeling, underlining the need for the acquisition of new MT measurements on Mt Vesuvius, particularly at high periods and with a higher resolution. The acquisition of data at these periods would help to place constraints on the deep magma feeding system.

\section{Acknowledgements}

This study is part of the $\mathrm{PhD}$ of A. P. The ISTO group thanks A. Siniscalchi and Z. Petrillo for having answered to solicitations at the beginning of this study. The authors are grateful to J. Tyburczy for his careful editorial work and thank A. Manzella as well as an anonymous reviewer for their comments. A.P. also thanks S. Rondenay for fruitful discussions. This study has been supported by the French national agency for research, ANR JC05-42707 (Electrovolc) attributed to F.G. MTInv is a free geophysical software by M. Pirttijärvi’s (http://www.cc.oulu.fi/ mpi/Softat/).

\section{References}

Aizawa, K., R. Yoshimura, N. Oshiman, K. Yamazaki, T. Uto, Y. Ogawa, S.B. Tank, W. Kanda, S. Sakanaka, Y. Furukawa, T. Hashimoto, M. Uyeshima, T. Ogawa, I. Shiozaki, A.W. Hurst (2005), Hydrothermal system beneath Mt. Fuji volcano inferred from magnetotellurics and electric self-potential, Earth Planet. Sci. Lett., 235 (1-2), 343-355.

Arnò V., C. Principe, M. Rosi, R. Santacroce, A. Sbrana, and M.F. Sheridan (1987), Eruptive history. In: Santacroce, R. (Ed.), Somma-Vesuvius. Quad. Ric. Sci., 114, pp. 53-103. 
Auger, E., P. Gasparini, J. Virieux, and A. Zollo (2001), Seismic evidence of an extended magmatic sill under Mt. Vesuvius, Science, 294 (5546), 1510-1512, doi:10.1126/science.1064893.

Ayuso, R. A., B. De Vivo, G. Rolandi, R. R. Seal, and A. Paone (1998), Geochemical and isotopic (Nd-Pb-Sr-O) variations bearing on the genesis of volcanic rocks from Vesuvius, Italy, J. Volcanol. Geotherm. Res., 82 (1-4), 53-78, doi:10.1016/S0377-0273(97)00057-7.

Balcone-Boissard, H., B. Villemant, G. Boudon, and A. Michel (2008), Non-volatile vs volatile behaviours of halogens during the AD79 plinian eruption of Mt. Vesuvius, Italy, Earth Planet. Sci. Lett., 269 (1-2), 66-79.

Berrino, G., G. Corrado, and U. Riccardi (1998), Sea gravity data in the Gulf of Naples: a contribution to delineating the structural pattern of the Vesuvian area, J. Volcanol. Geotherm. Res., 82, 139-150.

Berrino, G., and A.G. Camacho (2008), 3D Gravity Inversion by Growing Bodies and Shaping Layers at Mt. Vesuvius (Southern Italy), Pure Appl. Geophys., 165, 1095-1115.

Bianco, F., M. Castellano, G. Milano, G. Ventura, and G. Vilard (1998), The SommaVesuvius stress field induced by regional tectonics: evidences from seismological and mesostructural data, J. Volcanol. Geotherm. Res., 82 (1-4), 199-218.

Brocchini, D., C. Principe, D. Castradori, M.A. Laurenzi and L. Gorla (2001), Quaternary evolution of the southern sector of the Campanian Plain abd early Somma-Vesuvius activity: insights from the Trecase 1 well, Mineral. Petrol., 73 (1-3), 67-91.

Bruno, P.P.G., G. Cippitelli, and A. Rapolla (1998), Seismic study of the Mesozoic carbonate basement around Mt. Somma-Vesuvius, Italy, J. Volcanol. Geotherm. Res., 84, 311-322.

Caliro, S., G. Chiodini, R. Avino, C. Cardellini, F. Frondini (2005), Volcanic degassing at Somma-Vesuvio (Italy) inferred by chemical and isotopic signatures of groundwater, Applied Geochem., 20 (6), 1060-1076.

Caricchi, L., L. Burlini, and P. Ulmer (2008), Propagation of P and S-waves in magmas with different crystal contents: Insights into the crystallinity of magmatic reservoirs, $J$. Volcanol. Geotherm. Res., 178 (4), 740-750. 
Cassano, E. and P. La Torre (1987) Geophysics. In: Santacroce, R. (Ed.), SommaVesuvius, Quad. Ric. Sci., 114, 103-131.

Cella, F., M. Fedi, G. Florio, M. Grimaldi, and A. Rapolla (2007), Shallow structure of the Somma-Vesuvius volcano from 3D inversion of gravity data, J. Volcanol. Geotherm. Res., 161, 303-317.

Chiodini, G., L. Marini, and M. Russo, Geochemical evidence for the existence of hightemperature hydrothermal brines at Vesuvio volcano, Italy, Geochim. Cosmochim. Acta, 65 (13), 2129-2147.

Cioni, R., L. Civetta, P. Marianelli, N. Metrich, R. Santacroce, and A. Sbrana (1995), Compositional layering and syn-eruptive mixing of a periodically refilled shallow magma chamber: The AD 79 Plinian eruption of Vesuvius, J. Petrol., 36 (3), 739-776.

Cioni, R., P. Marianelli and R. Santacroce (1998) Thermal and compositional evolution of the shallow magma chambers of Vesuvius: Evidence from pyroxene phenocrysts and melt inclusions, J. Geophys. Res., 103, B8, 18277-18294.

Cioni R., R. Santacroce, and A. Sbrana (1999), Pyroclastic deposits as a guide for reconstructing the multi-stage evolution of the Somma-Vesuvius caldera, Bull. Volcanol., 60, 207-222.

Civetta, L., and R. Santacroce (1992), Steady state magma supply in the last 3400 years of Vesuvius activity, Acta Vulcanol., 2, 147-159.

Civetta, L., M. D’Antonio, S. de Lorenzo, V. di Renzo, and P. Gasparini (2004), Thermal and geochemical constraints on the 'deep' magmatic structure of Mt. Vesuvius, J. Volcanol. Geotherm. Res., 133, 1-12.

De Matteis, R., D. Latorre, A. Zollo, and J. Virieux (2000), 1D P-velocity models of Mt. Vesuvius volcano from the inversion of TomoVes96 first arrival time data, Pure Appl. Geophys., 157, 1643-1661.

De Natale, G., S. Petrazzuoli, C. Troise, F. Pingue, and P. Capuano, (2000), Internal stress field at Mt. Vesuvius : a model for background seismicity at a central volcano, $J$. Geophys. Res., 105 (B7), 16207-16214. 
De Natale, G., C. Troise, R. Trigila, D. Dolfi, and C. Chiarabba (2004), Seismicity and 3D substructure at Somma-Vesuvius volcano: evidence for magma quenching, Earth Planet. Sci. Lett., 221 (1-4), 181-196.

De Natale, G., C. Troise, F. Pingue, G. Mastrolorenzo, and L. Pappalardo (2006), The Somma-Vesuvius volcano (Southern Italy): Structure, dynamics and hazard evaluation, Earth-Science Reviews, 74 (1-2), 73-111.

Di Maio, R., P. Mauriello, D. Patella, Z. Petrillo, S. Piscitelli, and A. Siniscalchi (1998), Electric and electromagnetic outline of the Mt. Somma-Vesuvius structural setting, $J$. Volcanol. Geotherm. Res., 82 (1-4), 219-238, doi:10.1016/S0377-0273(97)00066-8.

Di Renzo, V., M.A. Di Vito, I. Arienzo, A. Caradente, L. Civetta, M. D’Antonio, F. Giordano, G. Orsi and S. Tonarini (2007) Magmatic history of Somma-Vesvius on the basis of new geochemical and isotopic data from a deep borehole (Camaldoli della Torre), J. Petrol., 48 (4), 753-784.

Ferrucci, F., G. Gaudiosi, N.A. Pino, G. Luongo, A. Hirn, and L. Mirabile (1989), Seismic detection of a major Moho upheaval beneath the Campania volcanic area (Naples, Southern Italy), Geophys. Res. Lett., 16, 1317-1320.

Fulignati, P., P. Marianelli, R. Santacroce, and A. Sbrana (2004a), Probing the Vesuvius magma chamber-host rock interface through xenoliths, Geol. Mag., 141 (4), 417-428, doi:10.1017/S0016756804009392.

Fulignati, P., P. Marianelli, N. Métrich, R. Santacroce, and A. Sbrana (2004b), Towards a reconstruction of the magmatic feeding system of the 1944 eruption of Mt Vesuvius, $J$. Volcanol. Geotherm. Res., 133, 13-22.

Glover, P. W. J., M. J. Hole, and J. Pous (2000), A modified Archie's law for two conducting phases, Earth Planet. Sci. Lett., 180 (3-4), 369-383, doi:10.1016/S0012821X(00)00168-0.

Hashin, Z., and S. Shtrikman (1962), On some variational principles in anisotropic and nonhomogeneous elasticity, J. Mech. Phys. Solids, 10, 335-342. 
Iacono-Marziano, G., F. Gaillard, B. Scaillet, M. Pichavant, and G. Chiodini (2009), Role of non-mantle CO2 in the dynamics of volcano degassing: The Mt. Vesuvius example, Geology, G25446.

Joron, J.L., N. Métrich, M. Rosi, R. Santacroce, and A. Sbrana (1987), Chemistry and petrography, In: Santacroce, R. (Ed.), Somma-Vesuvius, Quad. Ric. Sci., 114, 197-234.

Kagiyama, T., H. Utada, T. Yamamoto (1999), Magma ascent beneath Unzen Volcano, SW Japan, deduced from the electrical resistivity structure, J. Volcanol. Geotherm. Res., 89 (1-4), 35-42.

Lomax, A., A. Zollo, and P. Capuano (2001), Precise, absolute, earthquake location under Somma Vesuvius using a new 3D velocity model, Geophys. J. Int., 146, 316-331.

Mackie, R.L., T.R. Madden, and P.E. Wannamaker (1993), Three-dimensional magnetotelluric modeling using difference equation - Theory and comparisons to integral equation solutions, Geophysics, 58, 215-226.

Mainprice, D. (1997), Modelling the anisotropic seismic properties of partially molten rocks found at mid-ocean ridges, Tectonophysics, 279 (1-4), 161-179.

Manzella, A., G. Volpi, A. Zaja, and M. Meju (2004), Combined TEM-MT investigation of shallow-depth resistivity structure of Mt. Somma-Vesuvius, J. Volcanol. Geotherm. Res., 131 (1-2), 19-32, doi:10.1016/S0377-0273(03)00313-5.

Marianelli, P., N. Métrich, R. Santacroce, and A. Sbrana (1995), Mafic magma batches at Vesuvius: a glass inclusion approach to the modalities of feeding stratovolcanoes, Contrib. Mineral. Petrol., 120, 159-169.

Marianelli, P., N. Metrich, A. Sbrana (1999), Shallow and deep reservoirs involved in magma supply of the 1944 eruption of Vesuvius, Bull. Volcanol., 61, 48-63.

Marianelli, P., A. Sbrana, N. Métrich, and A. Cecchetti (2005), The deep feeding system of Vesuvius involved in recent violent strombolian eruptions, Geophys. Res. Lett., 32, L02306, doi:10.1029/2004GL021667.

Marzocchi, W., R. Scandone, and F. Mulargia (1993), The tectonic setting of Mt. Vesuvius and the correlation between its eruptions and the earthquakes of the Southern Apennines, J. Volcanol. Geotherm. Res., 58, 27-41. 
Matsushima, N., H. Oshima, Y. Ogawa, S. Takakura, H. Satoh, M. Utsugi, Y. Nishida (2001), Magma prospecting in Usu volcano, Hokkaido, Japan, using magnetotelluric soundings, J. Volcanol. Geotherm. Res., 109, 263-277.

Müller, M., A. Hordt, and F.M. Neubauer (1999), Electromagnetic technique’s success at Vesuvius points to use in forecasting eruptions, EOS Trans., 80, 393-401.

Müller, A., and V. Haak (2004), 3-D modeling of the deep electrical conductivity of Merapi volcano (Central Java): integrating magnetotellurics, induction vectors and the effects of steep topography, J. Volcanol. Geotherm. Res., 138 (3-4), 205-222.

Nunziata, C., M. Natale, G. Luongo, and G. F. Panza (2006), Magma reservoir at Mt. Vesuvius: Size of the hot, partially molten, crust material detected deeper than $8 \mathrm{~km}$, Earth Planet. Sci. Lett., 242 (1-2), 51-57, doi:10.1016/j.epsl.2005.12.002.

Panza, G.F., A. Peccerillo, A. Aoudia, B. Farina (2007), Geophysical and petrological modelling of the structure and composition of the crust and upper mantle in complex geodynamic settings: The Tyrrhenian Sea and surroundings, Earth-Science Reviews, 80 (1-2), 1-46.

Pirttijärvi, M. (2004), MTInv, 1-D interpretation of magnetotelluric EM soudings, version 1.3 manual. University of Oulu, 8pp.

Pommier, A., F. Gaillard, M. Pichavant, and B. Scaillet (2008), Laboratory measurements of electrical conductivities of hydrous and dry Mt. Vesuvius melts under pressure, $J$. Geophys. Res., 113, B05205, doi:10.1029/2007JB005269.

Principe, C., D. Brocchini, and M. Perillo (1999), The "Cognoli di Trocchia” volcano and Monte Somma growth. Plinius, 22, 316 -317.

Quist, A. S., and W. L. Marshall (1968), Electrical conductances of aqueous sodium chloride solutions from 0 to $800^{\circ} \mathrm{C}$ and at pressures to 4000 bars, J. Phys. Chem., 72, 684703.

Rolandi, G., G. Mastrolenzo, A.M. Barrella, and A. Borrelli (1993), The Avellino plinian eruption of Somma-Vesuvius (3,760 y. B.P.): the progressive evolution from magmatic to hydromagmatic style, J. Volcanol. Geotherm. Res., 58, 67-88. 
Rondenay, S., L. G. J. Montési, and G. A. Abers, New geophysical insight into the origin of the Denali volcanic gap, submitted.

Rosi, M., and R. Santacroce (1983), The AD 472 "Pollena” eruption: Volcanological and petrological data for this poorly-known, Plinian-type event at Vesuvius, J. Volcanol. Geotherm. Res., 17 (1-4), 249-271, doi:10.1016/0377-0273(83)90071-9.

Rosi, M., R. Santacroce, and M.F. Sheridan, (1987), Volcanic hazard. In: Santacroce, R. (Ed.), Somma-Vesuvius. Quad. Ric. Sci., 114, 197-234.

Santacroce, R., 1983. A general model for the behavior of the Somma-Vesuvius volcanic complex. J. Volcanol. Geotherm. Res., 17, 237-248.

Santacroce, R. (Ed.) (1987), Somma-Vesuvius, Quad. Ric. Sci., 114 (8), 230 pp.

Santacroce, R., A. Bertagnini, L., Civetta, P., Landi, A., Sbrana (1993), Eruptive dynamics and petrogenetic processes in a very shallow magma reservoir : The 1906 eruption of Vesuvius, J. Petrol., 34, 383-425.

Santacroce, R., R. Cioni, L. Civetta, P. Marianelli, and N. Métrich (1994), How Vesuvius works, Atti Conv. Lincei, 112, 185-196.

Santacroce, R., R. Cioni, P. Marianelli, and A. Sbrana (2005), Understanding Vesuvius and preparing for its next eruption, in Cultural Responses to the Volcanic Landscape: The Mediterranean and Beyond, edited by M. S. Balmuth et al., pp. 27-55, Archeol. Inst. of Am., Boston, Mass.

Santacroce, R., R. Cioni, P. Marianelli, A. Sbrana, R. Sulpizio, G. Zanchetta, D. J. Donahue, and J.- L. Joron (2008), Age and whole rock-glass compositions of proximal pyroclastics from the major explosive eruptions of Somma-Vesuvius: A review as a tool for distal tephrostratigraphy, J. Volcanol. Geotherm. Res., 177 (1), 1-18.

Scaillet, B., M. Pichavant, and R. Cioni (2008), Upward migration of Vesuvius magma chamber over the past 20,000 years, Nature, 455, 216-219, doi:10.1038/nature07232.

Scandone, R., L. Giacomelli, and P. Gasparini (1993), Mt. Vesuvius: 2000 years of volcanological observations, J. Volcanol. Geotherm. Res., 58, 5-25. 
Scandone, R., L. Giacomelli, and F. Fattori Speranza (2008), Persistent activity and violent strombolian eruptions at Vesuvius between 1631 and 1944, J. Volcanol. Geotherm. Res., 170, 167-180.

Simpson, F., and K. Bahr (2005), Practical Magnetotellurics, Cambridge University Press, 270 pp.

Taylor, M.A.J., and S.C. Singh (2002), Composition and microstructure of magma bodies from effective medium theory, Geophys. J. Int., 149 (1), 15-21.

Ten Grotenhuis, S.M., M.R. Drury, C.J. Spiers, and C.J. Peach (2005), Melt distribution in olivine rocks based on electrical conductivity measurements, J. Geophys. Res., 110, B12201, doi: 10.1029/2004JB003462.

Troiano, A., Z. Petrillo, M. G. Di Giuseppe, M. Balasco, I. Diaferia, B. Di Fiore, A. Siniscalchi, and D. Patella (2008), About the shallow resistivity structure of Vesuvius volcano, Annals Geophys., 51 (1), 181-189.

Umeda K., K. Asamori, T. Negi, Y. Ogawa (2006), Magnetotelluric imaging of crustal magma storage beneath the Mesozoic crystalline Mt.ains in a nonvolcanic region, northeast Japan, Geochem. Geophys. Geosyst., 7, Q08005, doi:10.1029/2006GC001247.

Villemant, B., R. Trigila, and B. DeVivo (1993) Geochemistry of Vesuvius volcanics during 1631-1944 period, J. Volcanol. Geotherm. Res., 58 (1-4), 291-313.

Wannamaker, P.E., D.P. Hasterok, , J.M. Johnston, J.A. Stodt, D.B. Hall, T.L. Sodergren, L. Pellerin, V. Maris, W.M. Doerner, K.A. Groenewold, and M.J. Unsworth, (2008), Lithospheric dismemberment and magmatic processes of the Great Basin-Colorado Plateau transition, Utah, implied from magnetotellurics, G cubed, 9(5), 1-38, Q05019, doi:10.1029/2007GC001886.

Whaler, K.A., and S. Hautot (2006), The electrical resistivity structure of the crust beneath the northern Main Ethiopian Rift, from: Yirgu, G., Ebinger, C.J. Maguire, P.K.H. (eds) 2006. The Afar Volcanic Province within the East African Rift System. Geological Society, London, Special Publications, 259, 293-305. 
Zimmer, M., and J. Erzinger (1998), Geochemical monitoring on Merapi volcano, Indonesia, Mitt. Dtsch. Geophysik. Ges. e.V., DGG Spec. Vol. 3 (ISSN 0947-1944), pp. 89-92.

Zollo, A., P. Gasparini, J. Virieux, H. le Meur, G. de Natale, G. Biella, E. Boschi, P. Capuano, R. de Franco, P. dell'Aversana, R. de Matteis, I. Guerra, G. Iannaccone, L. Mirabile, G. Vilardo (1996), Seismic evidence for a low-velocity zone in the upper crust beneath Mt. Vesuvius, Science, 274(5287), 592-594, doi:10.1126/science.274.5287.592.

Zollo, A., P. Gasparini, J. Virieux, G. Biella, E. Boschi, P. Capuano, R. de Franco, P. Dell'Aversana, R. de Matteis, G. De Natale, G. Iannaccone, I. Guerra, H. Le Meur and L. Mirabile (1998), An image of Mt. Vesuvius obtained by 2D seismic tomography, J. Volcanol. Geotherm. Res., 82(1-4), 161-173, doi:10.1016/S0377-0273(97)00063-2.

Zollo, A., W. Marzocchi, P. Capuano, A. Lomax, and G. Iannacone (2002), Space and time behaviour of seismic activity at Mt. Vesuvius volcano, Southern Italy, Bull. Seismol. Soc. Am., 92, 625-640.

\section{Figure captions:}

Figure 1: Electrical resistivity of Mount Vesuvius magmas in pre-eruptive conditions for several past volcanic events, using the model of Pommier et al. [2008] and phase relation works from [Scaillet et al., 2008]. Magmatic compositions correspond to the Pompei, the zoned Pollena and 1631 eruptions and the last 1944 volcanic event. Calculations were performed assuming crystals as clinopyroxenes. Dots represent the phenocryst contents of the eruptive products.

Figure 2: Location map of the Somma-Mount Vesuvius volcanic area (after Manzella et al. [2004]) and location of MT soundings. Boxes with site numbers and profiles AA' and BB' from Manzella et al. [2004]. Ellipses with site numbers and profile CC' from DiMaio et al. [1998]. Sites 8 and 9 from Manzella et al. are not presented since no transfer functions are available for these stations and site 6 was discarded because transfer functions were only partially recorded for this station. ex, ey and ez indicate the $\mathrm{x}, \mathrm{y}$ and $\mathrm{z}$ directions, respectively, used for the 3-D forward model presented in the present study. TC: Trecase well. 
Figure 3: Comparison between apparent resistivity curves from DiMaio et al. [1998] (DM) and Manzella et al. [2004] (M) for two close observation sites (see Figure 2) on Mt Vesuvius. A systematic shift of about 2log-units is observed between the curves from the two studies (underlined by the double narrow), whatever the position of the volcano. The data from DiMaio et al. are probably affected by static shift (see text for details). The rectangle serves to locate the position of the systematic minimum in the curves (between 0.4 and $7 \mathrm{~s})$.

Figure 4: Example of 3-D model of the electrical resistivity distribution under Mount Vesuvius volcano. The figures on the cube edges are in $\mathrm{km}$. A) External view of the model. Layers characteristics presented in Table 2. B) Cut in the middle of the structure, showing the presence of a magma chamber $(8 \mathrm{~km} 3$, at $7.5 \mathrm{~km}$ depth, with a resistivity of $20 \mathrm{ohm} . \mathrm{m})$. The sea was taken into account in the boundary conditions. Note that a homogeneous half space $(20 \mathrm{ohm} . \mathrm{m})$ is placed at a depth $>60 \mathrm{~km}$.

Figure 5: Effect of a superficial conductor on the transfert functions (1-D model) and comparison with the data from Manzella et al. [2004] (M et al. 04). A) Effect of the resistivity of a $1 \mathrm{~km}$-thick layer placed at a depth of $0.6 \mathrm{~km}$ at site 3 in $\mathrm{M}$ et al. 04 (see Figure 2). Full line corresponds to the absence of a conductive layer in the model (initial model). B) Best fit to field data in Site 3 and Site 4, obtained with a about $1.1 \mathrm{~km}$-thick layer, at $0.6 \mathrm{~km}$ depth and with a resistivity of 4.7 and $40 \mathrm{hm} . \mathrm{m}$, respectively. C) Resistivity vs depths profiles (dashed lines) for each site in $\mathrm{M}$ et al. (04). The general 1-D model is represented by the full line.

Figure 6: Effect of a deep conductor on the transfert functions (1-D model) (Site 5, M et al. 04). A) Resistivity effect of a deep $1 \mathrm{~km}$-thick conductor placed at $8 \mathrm{~km}$ depth. Comparison with field response (xy (open circles) and yx curves (filled squares)) from Manzella et al. [2004] shows that the only presence of a deep conductor does not allow to reproduce the field response. B) Depth effect of a $1 \mathrm{~km}$-thick conductor with a resistivity of $20 \mathrm{ohm} . \mathrm{m}$, from 3 to $12 \mathrm{~km}$. C) Effect of the thickness of a $20 \mathrm{ohm} . \mathrm{m}$ conductive body placed at $8 \mathrm{~km}$ depth. In the three cases, the effect on the transfert functions is visible for periods $>0.1 \mathrm{~s}$.

Figure 7: Joint effect of a shallow and a deep conductor on the transfert functions (1-D simulations). Both conductors have a 4ohm.m resistivity. A) Effect on the transfert functions and comparison with the field data from Manzella et al. [2004] (M et al., 04, Site 3). The field data are reproduced by the only presence of a shallow conductor. The addition of a deep conductive body has a small effect on the apparent resistivity and phase curves. B) Resistivity profiles vs depth for the three configurations tested in A) (shallow conductor, deep conductor and shallow and deep conductors), pointing out the resistivity, thickness and depth of the conductors.

Figure 8: Effect of the depth of a deeper conductor in presence of a shallow conductive 
body (Site 3, Manzella et al. [2004]). Conditions of the shallow conductor correspond to the best fit in Figure 4 for Site 3 (resistivity of $\sim 5 \mathrm{ohm} . \mathrm{m}, 1 \mathrm{~km}$ thick, $0.6 \mathrm{~km}$ depth).

Decreasing the depth decreases the apparent resistivity (narrow). Increasing the depth fits better the field data. For comparison, results with only a shallow conductor (no deep conductor) are presented.

Figure 9: Effect of the volume of a deeper conductor in presence of a shallow conductive body (1-D and 3-D simulations). Same conditions on the shallow body as in Figure 8. A) Field and modelled transfert functions for Site 3 in Manzella et al. [2004]. The deep conductive body has a bulk resistivity of $20 \mathrm{ohm} . \mathrm{m}$, is placed at $8 \mathrm{~km}$ depth and is $1 \mathrm{~km}$ thick. Volumes were varied by changing in the $\mathrm{x}$ and $\mathrm{y}$ dimensions (see Figure 2 for spatial orientation). The curves are slightly affected by significant changes in volume reservoir (no visible differences between simulations with 4 and 8km3). B) Apparent resistivity values from $A$ ) as a function of the volume of the reservoir for different periods. This kind of representation clearly suggests that a voluminous chamber do not provide the best fit to field data. Regression lines are just a guide for the eye.

Figure 10: Effect of the resistivity of a deeper conductor in presence of a shallow conductive body (1-D simulations). Same conditions on the shallow body as in Figure 8. A) Field and modelled transfert functions for Site 3 in Manzella et al. [2004]. Deep conductive body placed at $8 \mathrm{~km}$ depth and is $2 \mathrm{~km}$ thick. No chamber simulation corresponds to a reservoir as resistive as the surrounding carbonates $(r=2000 \mathrm{ohm} . \mathrm{m})$. A significant effect is observed on the field response for very conductive deep body. B) Apparent resistivity values from A) as a function of the bulk resistivity of the reservoir for four different periods. For periods $>10$ s, the trend obtained suggest that high conductive deep body greatly affects apparent resistivities and thus does not reproduce the field response. Regression lines are just a guide for the eye.

Figure 11: Possible scenarios concerning the presence of a deep magma chamber below Mt. Vesuvius based on the results from the forward modelling of the resistivity and petrological and geophysical constraints. A first hypothesis (Hyp.1) considers a lowtemperature and crystal-rich magma. The second hypothesis (Hyp. 2) explains the deep geophysical anomaly by the presence of a hot (crystal-poor) magma interconnected within the surrounding carbonates. Models relating the seismic wave velocities to magma structure and properties [Mainprice, 1997] support Hyp.2. See text for details. 


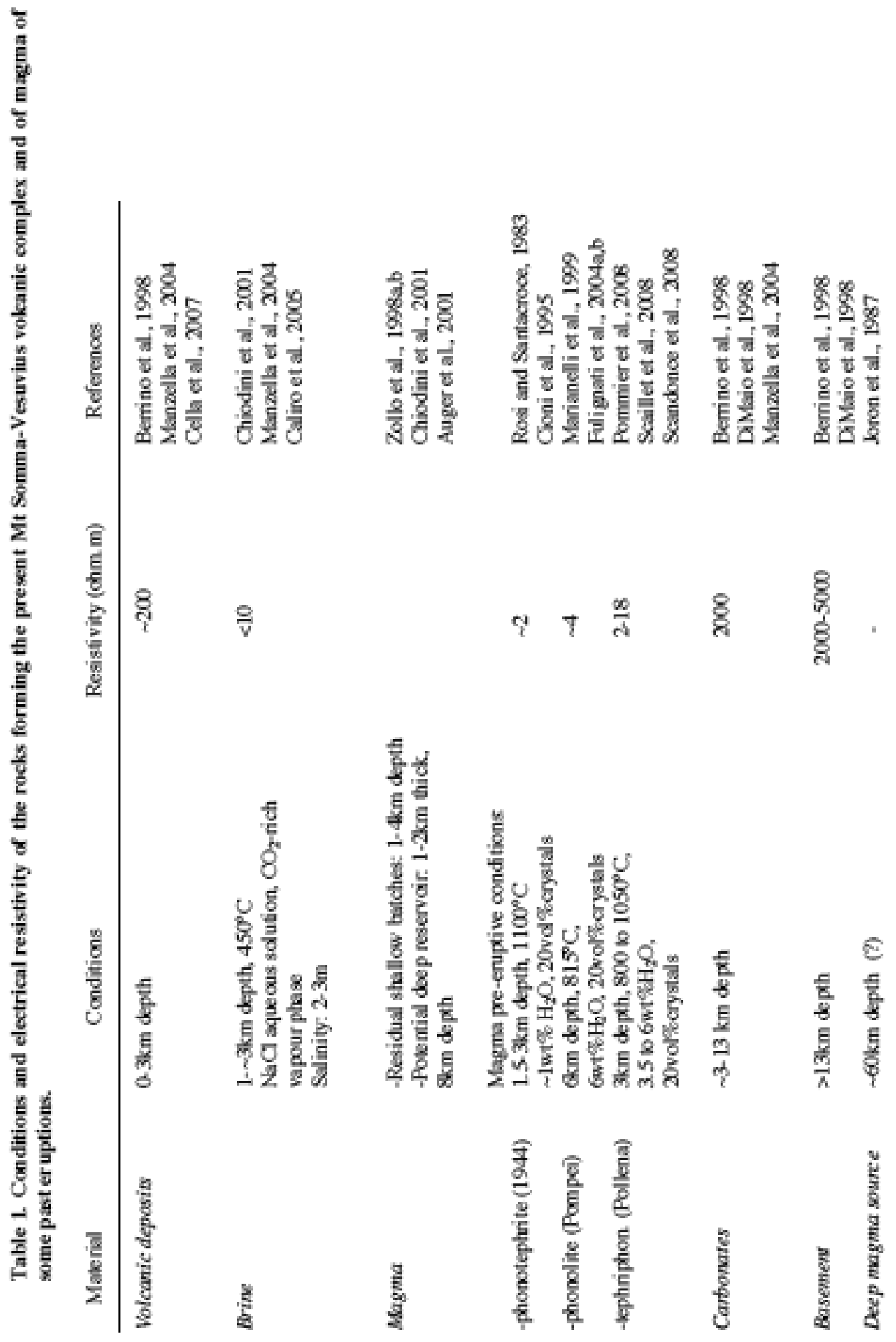




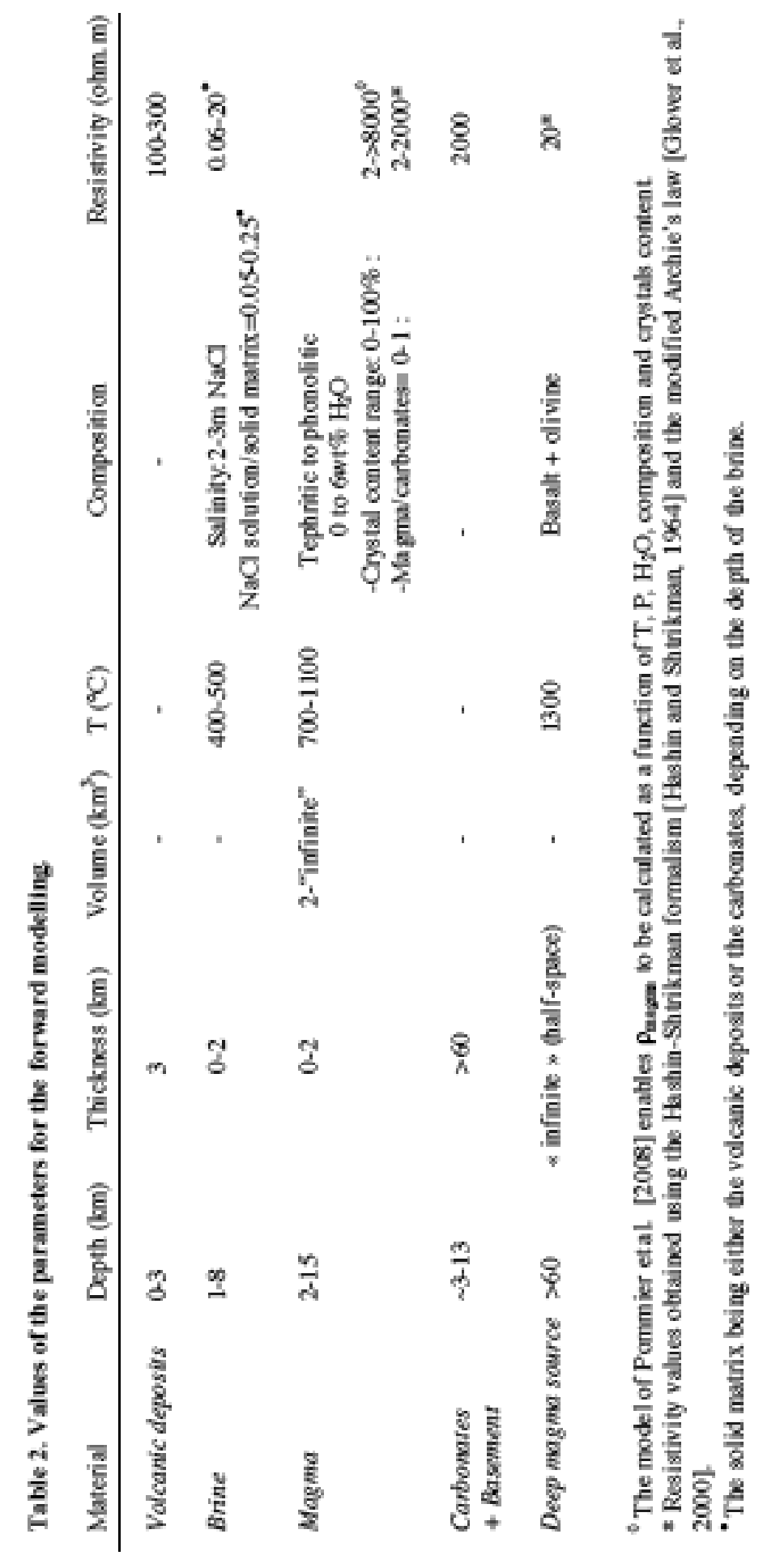




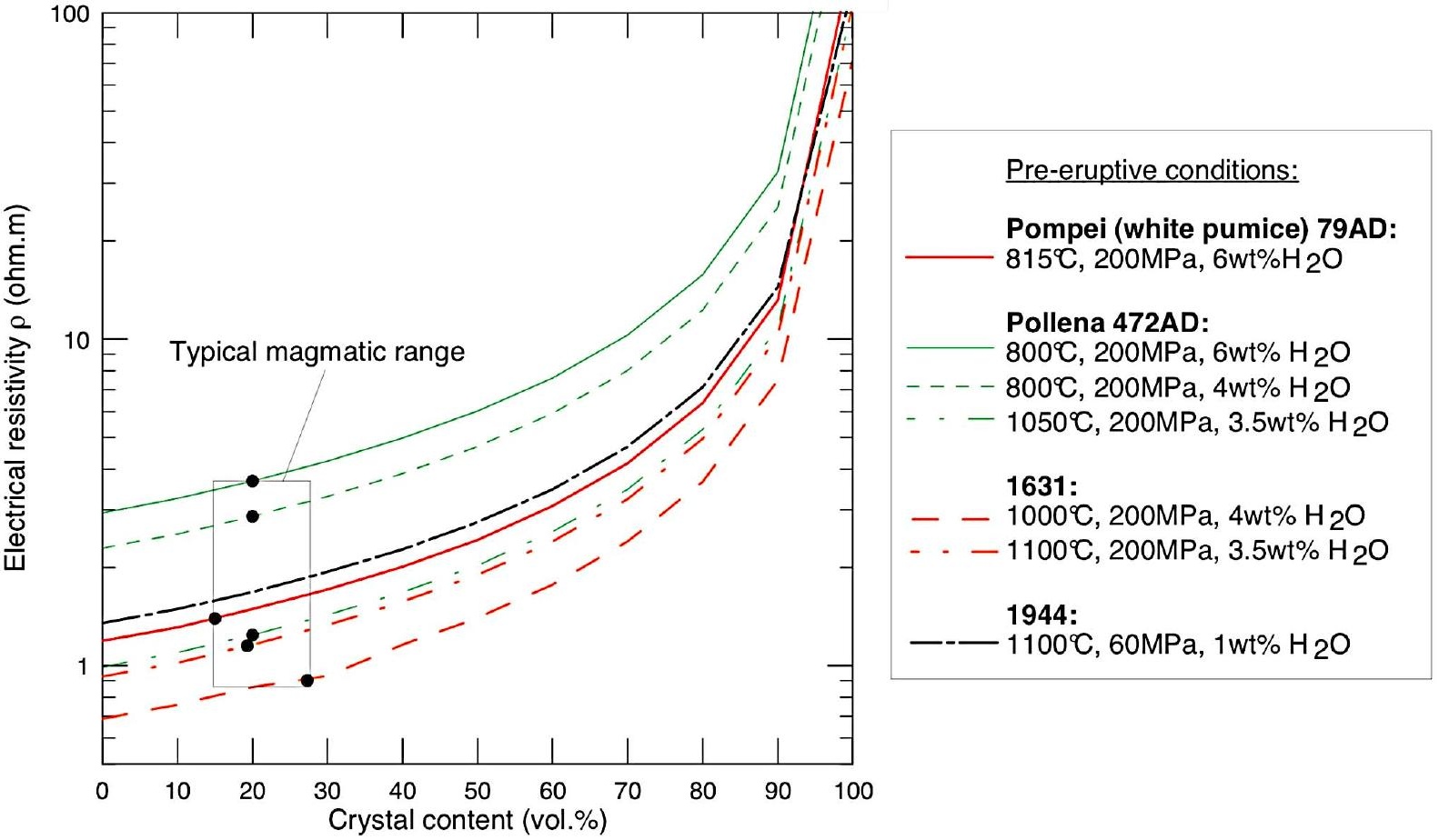




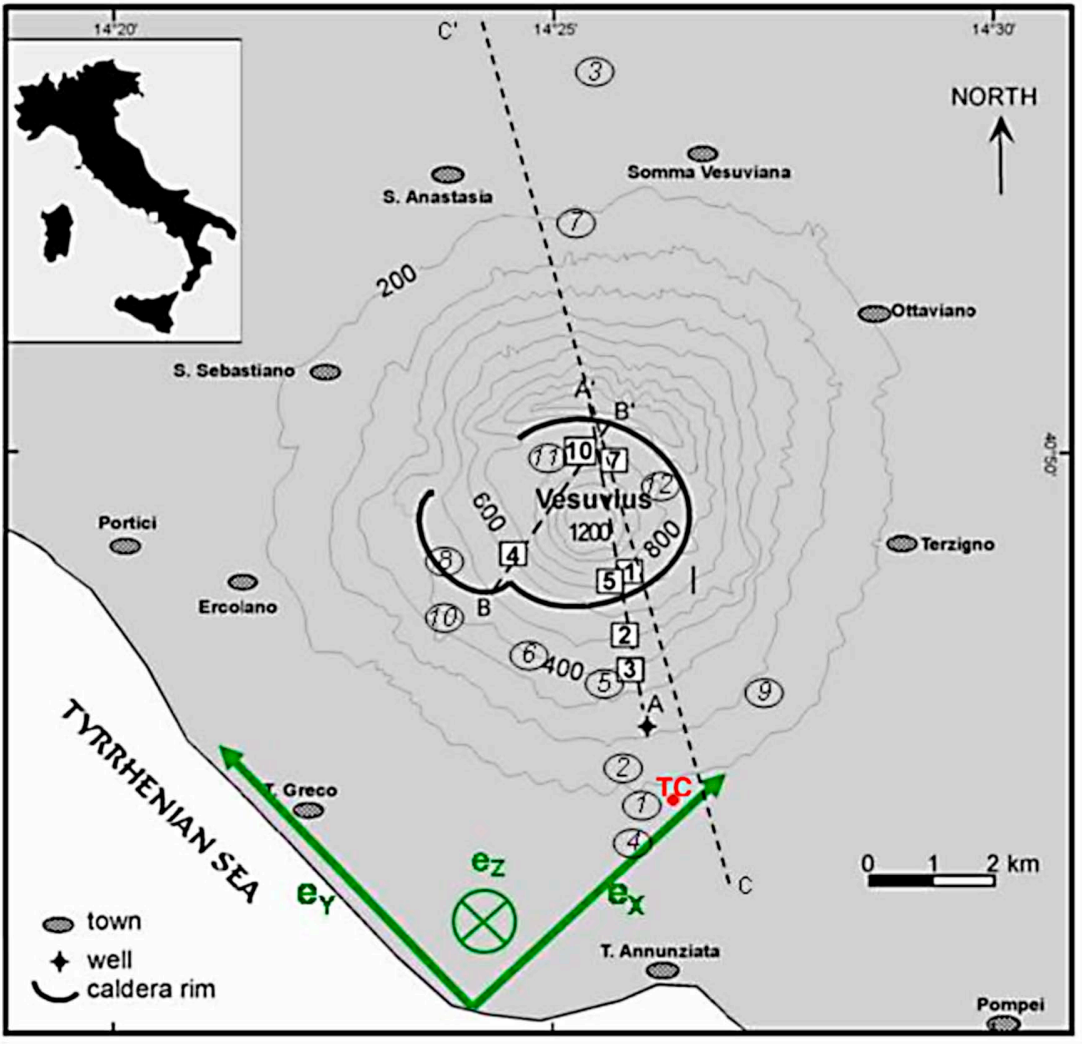



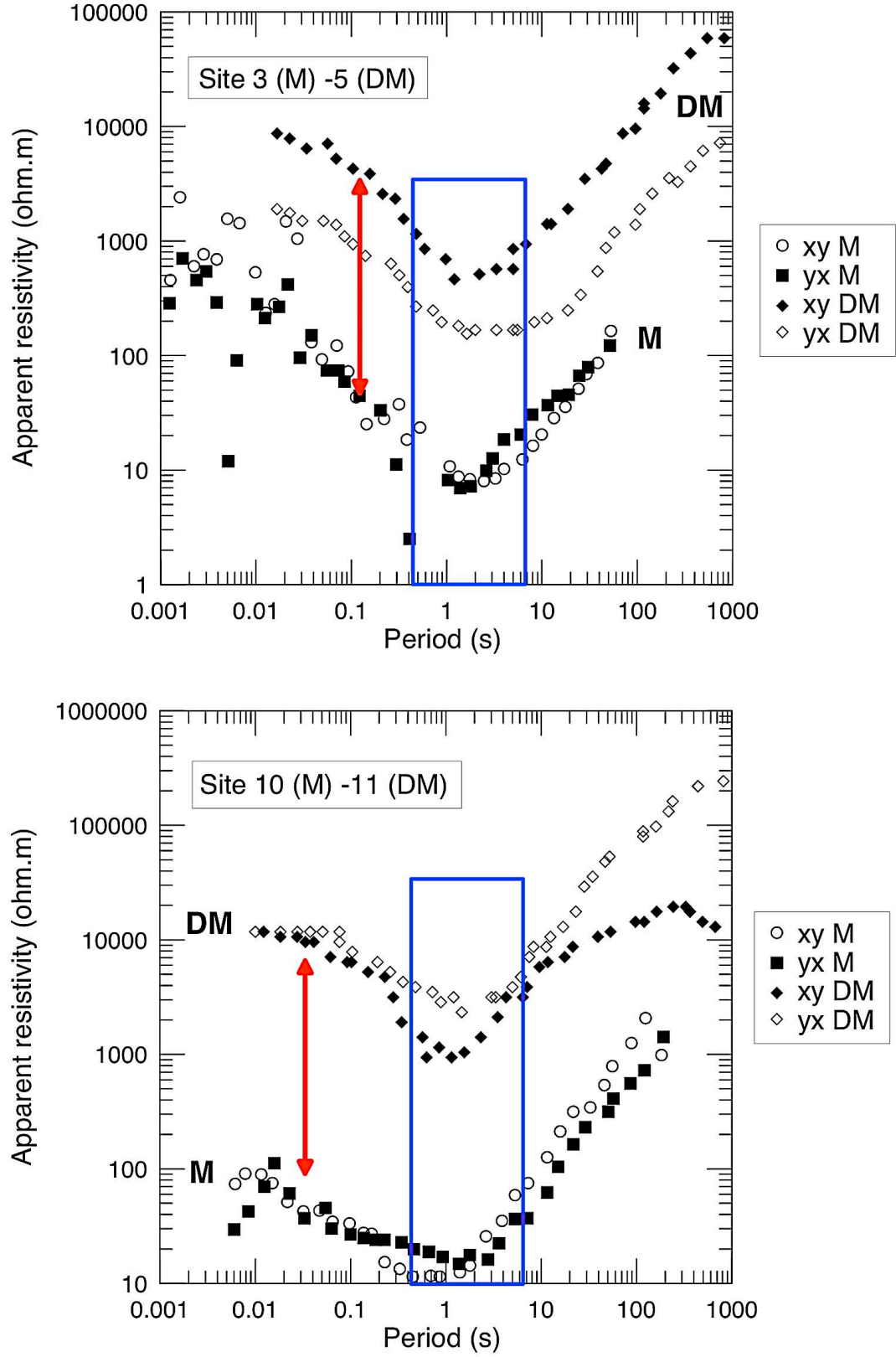
A
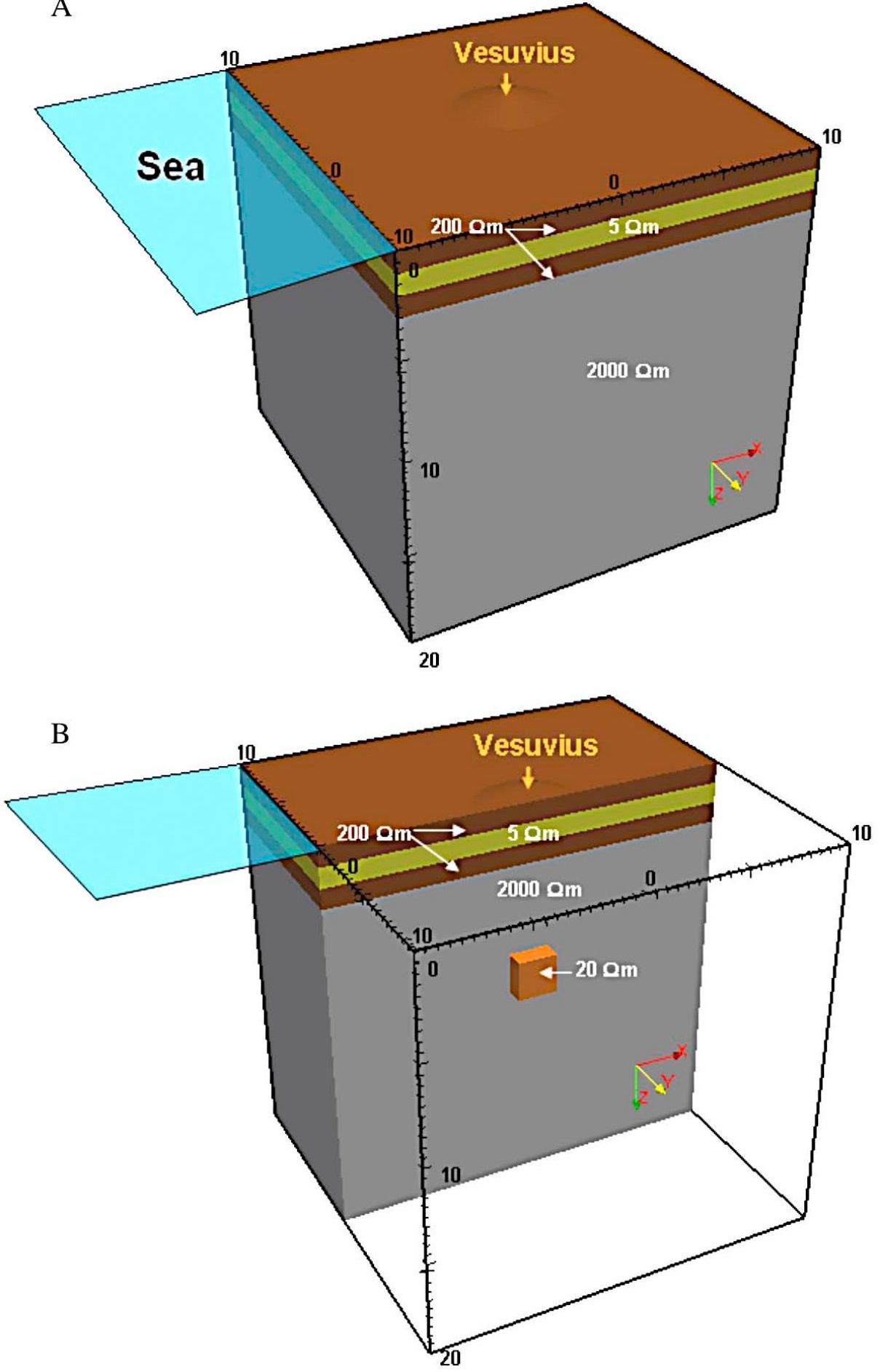


\section{A) Superficial conductor - effect of resistivity}
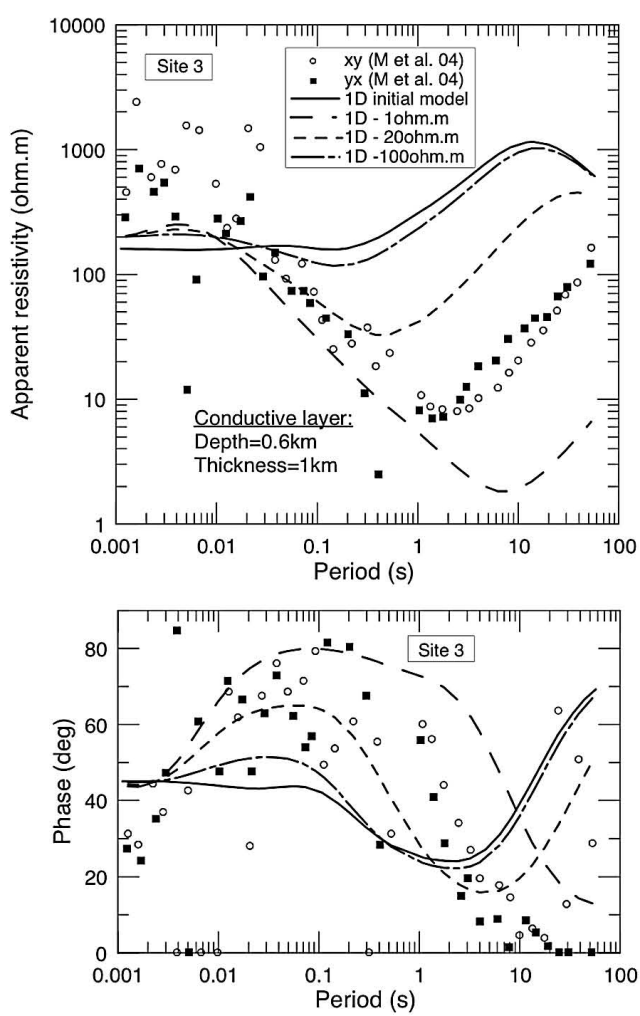

C) Superficial conductor - resistivity profiles vs depth

Resistivity (ohm.m)

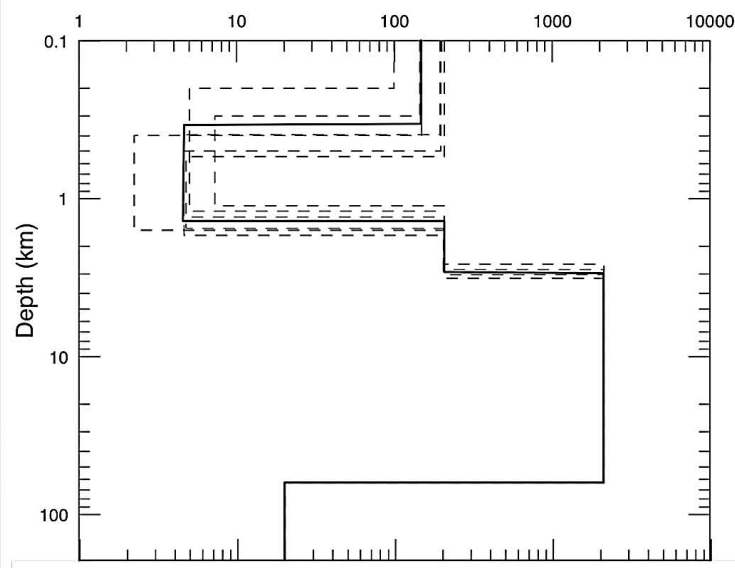

B) Superficial conductor - best fit
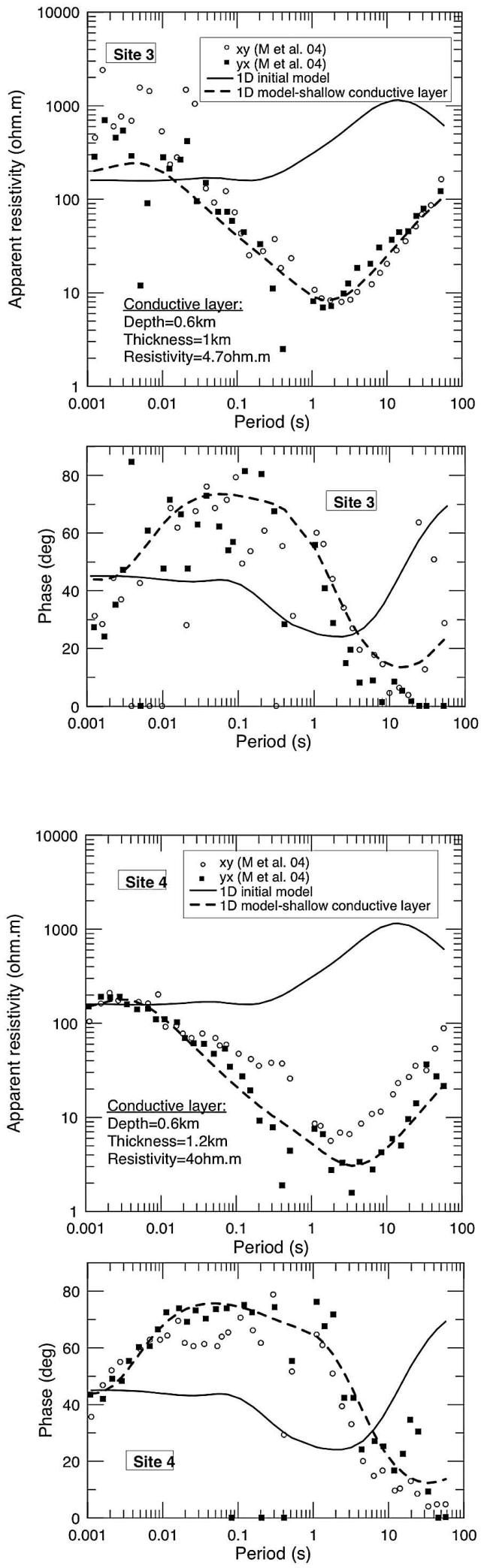
A)
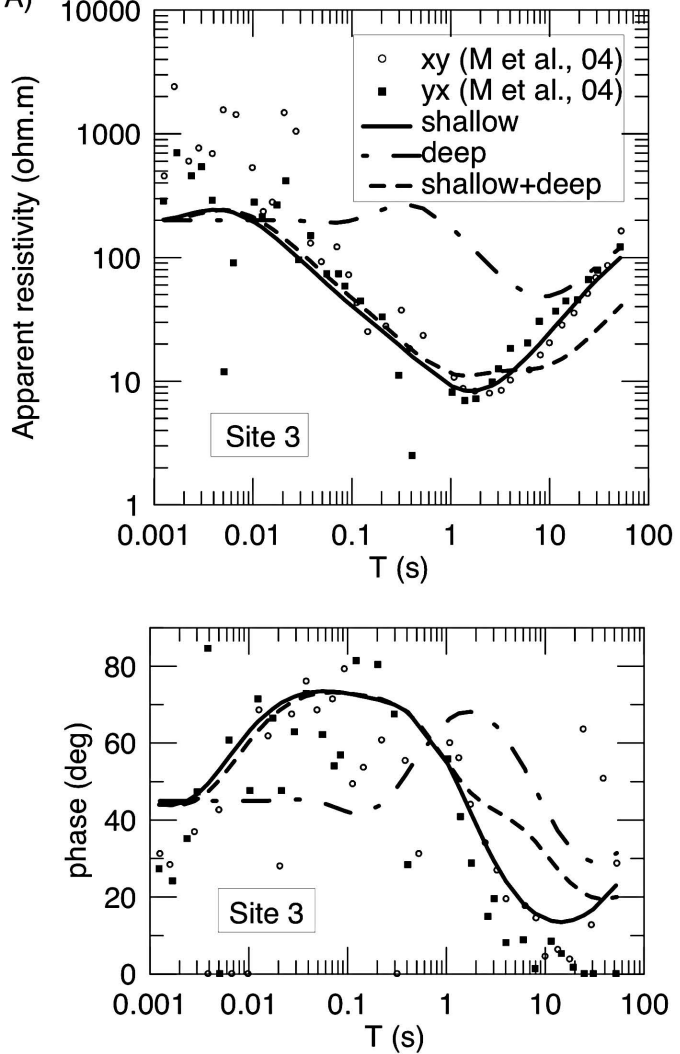

B)

Shallow

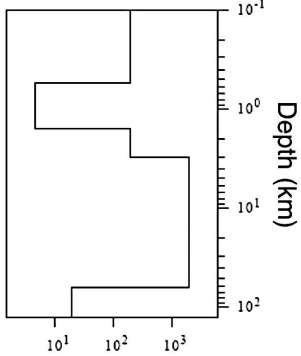

Resistivity (ohm.m)

Deep

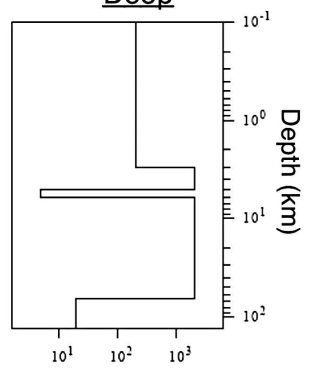

Resistivity (ohm.m)

\section{Shallow+Deep}

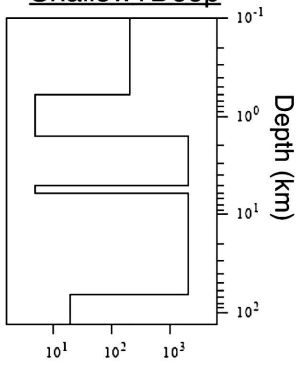

Resistivity (ohm.m) 

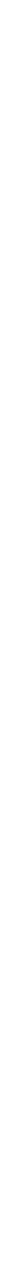
A)
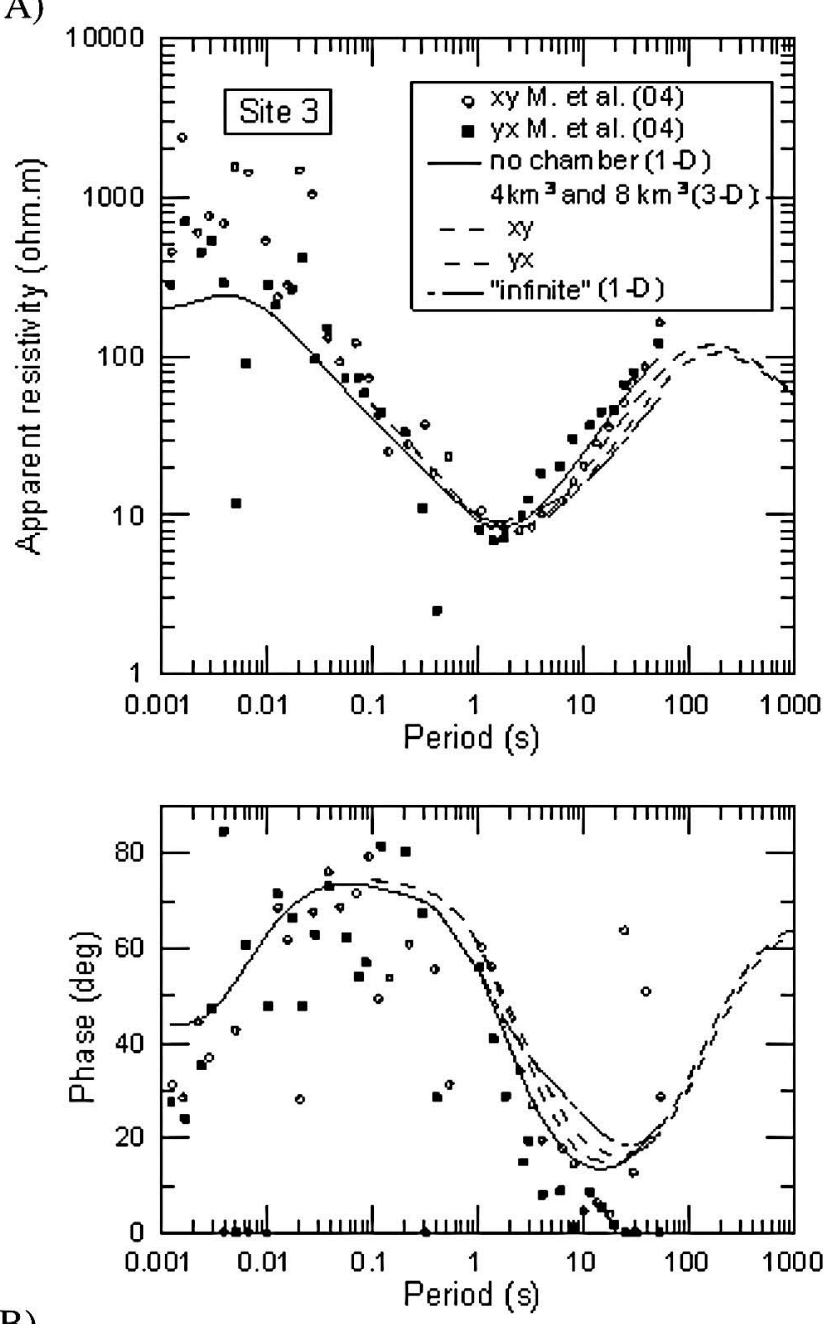

B)

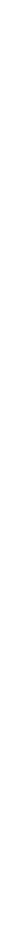



interconnected within carbonates

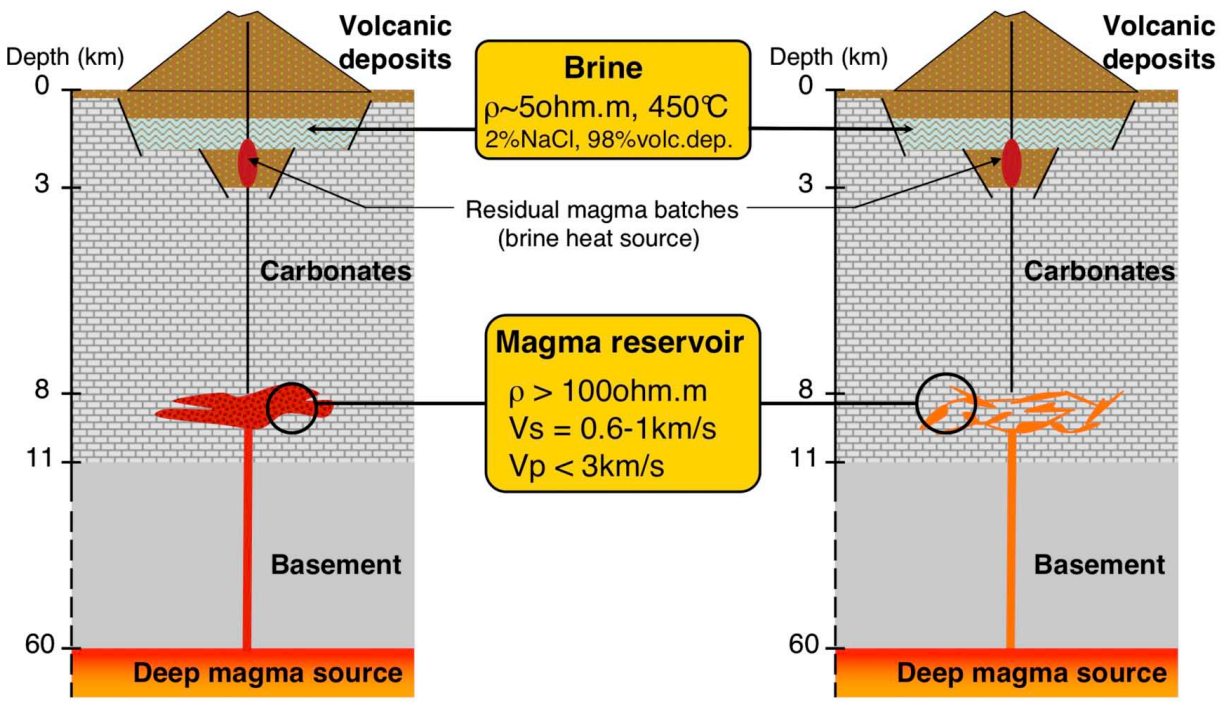

